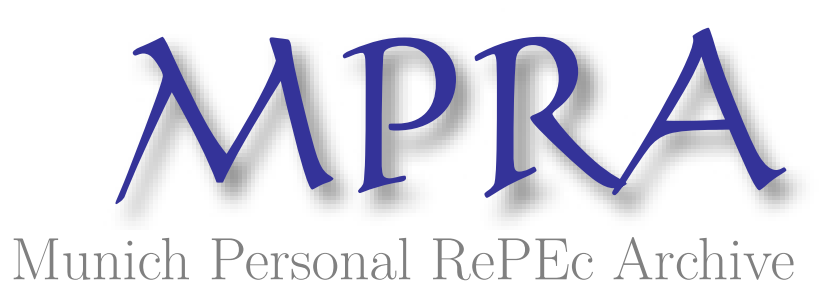

\title{
Unemployment, Partial Insurance, and the Multiplier Effects of Government Spending
}

Givens, Gregory

University of Alabama

November 2019

Online at https://mpra.ub.uni-muenchen.de/96811/

MPRA Paper No. 96811, posted 05 Nov 2019 17:23 UTC 


\title{
Unemployment, Partial Insurance, and the Multiplier Effects of Government Spending
}

\author{
Gregory E. Givens ${ }^{\mathrm{a}, *}$

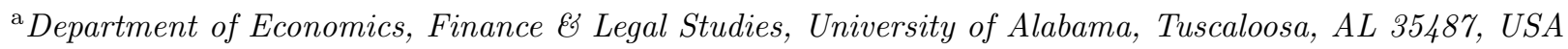

First Draft: November 2019

\begin{abstract}
I interpret the empirical evidence on government spending multipliers using an equilibrium model of unemployment in which workers are not fully insured against the risk of job loss. Consumption of resources by the government affects aggregate spending along two margins: $(i)$ an intensive margin owing to a fall in household wealth and $(i i)$ an extensive margin that accounts for growth in the working population. At insurance levels below a certain threshold, the positive effects of $(i i)$ dominate the negative effects of $(i)$, leading to multipliers for private consumption and output that exceed zero and one. Similar results appear in a quantitative version of the model scaled to match estimates from micro data on the consumption cost of unemployment.
\end{abstract}

Keywords: Government Spending Multipliers, Unemployment Insurance, Shirking Models JEL Classification: E13, E24, E32, E62, H50, J41

\footnotetext{
${ }^{*}$ Corresponding author. Tel.: + 2053488961 .

E-mail address: gegivens@cba.ua.edu (G.E. Givens).
} 


\section{Introduction}

There is no shortage of empirical research on the subject of government spending multipliers. For the U.S., plausible estimates linking government purchases to real GDP can be anywhere from around 0.8 to 1.5 (e.g., Ramey, 2011b). But whether a given estimate falls on the high or low end of this range very often depends on the contemporaneous behavior of private consumption. Many studies document a sizable increase in consumption, which alongside the rise in public spending, usually delivers a GDP multiplier well above one (e.g., Blanchard and Perotti, 2002; Galí, López-Salido, and Vallés, 2007; Fisher and Peters, 2010; Mertens and Ravn, 2010; Ben Zeev and Pappa, 2017). Others report weak or even slightly negative effects that in either case are not far from zero (e.g., Burnside, Eichenbaum, and Fisher, 2004; Mountford and Uhlig, 2009; Barro and Redlick, 2011; Ramey, 2011a). What none of these studies find, however, is any clear-cut evidence of a large drop in consumption, which is why estimates of the GDP multiplier are unlikely to be a lot lower than one.

The apparent absence of significant crowding-out effects in the data has long posed a challenge to neoclassical theory. As explained in Baxter and King (1993), the absorption of resources by the government generates a negative wealth effect that leads people to cut back on consumption and leisure. Longer work hours mitigate some of the consumption loss, but the downward pressure this exerts on the real wage serves only to reinforce the contraction in private spending. As a result, output multipliers for a temporary increase in government purchases tend to be substantially below unity.

In this paper I argue that the mismatch between theory and evidence may be illusory. Strictly speaking, observed multipliers need not be inconsistent with the neoclassical dynamic at all. This can happen if the wealth effects, which theory tells us should occur at the household level, are being obscured in the data by factors not normally present in business cycle models. Here I focus on just two: unemployment in the labor market and a risk-sharing arrangement that departs from the usual assumption of full insurance. How their interaction makes it harder to detect any crowding out of private consumption can be illustrated with a simple thought experiment. Consider an unanticipated increase in government purchases that lifts output by raising the number of employed persons. If all workers are fully insured against the risk of job loss, a shift in the composition of the labor force away from unemployment will not affect the aggregate level of consumption in the economy. But if workers are only partially insured, this composition effect will push up aggregate consumption at the same time the wealth effects of government spending push it down. To be clear, the former represents an extensive rather than intensive margin of adjustment. And should it outweigh 
the latter, efforts to identify a negative response in the data could fail. ${ }^{1}$

I formalize this idea using the shirking, efficiency-wage model developed by Alexopoulos (2004). In this setup unemployment arises endogenously from firms' inability to monitor effort. Unemployment insurance, on the other hand, enters exogenously by means of an income-pooling device that can accommodate a continuum of risk-sharing options from partial to full insurance. An advantage of this model is that it is simple enough for the effects of government spending to be evaluated analytically. That way the policy consequences of varying the degree of unemployment insurance are completely transparent.

The main theoretical results are summarized by a pair of mathematical propositions showing that multipliers for aggregate consumption and output will be greater than zero and one if the amount of unemployment insurance held by individuals is below some critical value. Unlike much of the relevant literature though, the shirking model doesn't need stickiness in the price level to be effective. Nor do the multipliers suddenly become smaller when allowing for investment dynamics. This is because government spending affects the economy through a labor supply mechanism that functions the same when prices are flexible or sticky and when capital is fixed or variable. That mechanism, it turns out, is closely related to others from the literature that transmit policy shocks through an inversion of the aggregate labor supply curve. The equivalent reduced-form concept here is the "no-shirking condition" originating from the incentive compatibility constraint on effort (e.g., Shapiro and Stiglitz, 1984; Kimball, 1994). One can show that the wage-employment locus implied by this condition is horizontal under full insurance but slopes downward under partial insurance.

That the mechanism described above has the potential to explain observed multipliers does not mean the results themselves should be taken seriously. How convincing the results are depends instead on the empirical validity of two criteria central to the analysis. One of those criteria is that government spending produce more workers and fewer nonworkers in the short run. Unfortunately, studies that probe aggregate data for evidence of this dynamic often have little to say. To the extent labor market effects are discussed at all, the focus is almost always on intensive-margin quantities such as hours worked and average productivity. $^{2}$ For this reason, I present some evidence of my own on the extensive-margin effects of a shock to government purchases. Like most of the literature, identification is

\footnotetext{
${ }^{1}$ This line of argument implicitly assumes that the total size of the labor force is fixed in the short run and that consumption of individuals not in the labor force is more or less invariant to spending shocks.

${ }^{2}$ Notable exceptions include Ravn and Simonelli (2007) and Monacelli, Perotti, and Trigari (2010). Both sets of authors find that in the U.S., unemployment falls significantly after a positive shock to government spending. Brückner and Pappa (2012) report similar results in a subsample covering the period 1968-1980.
} 

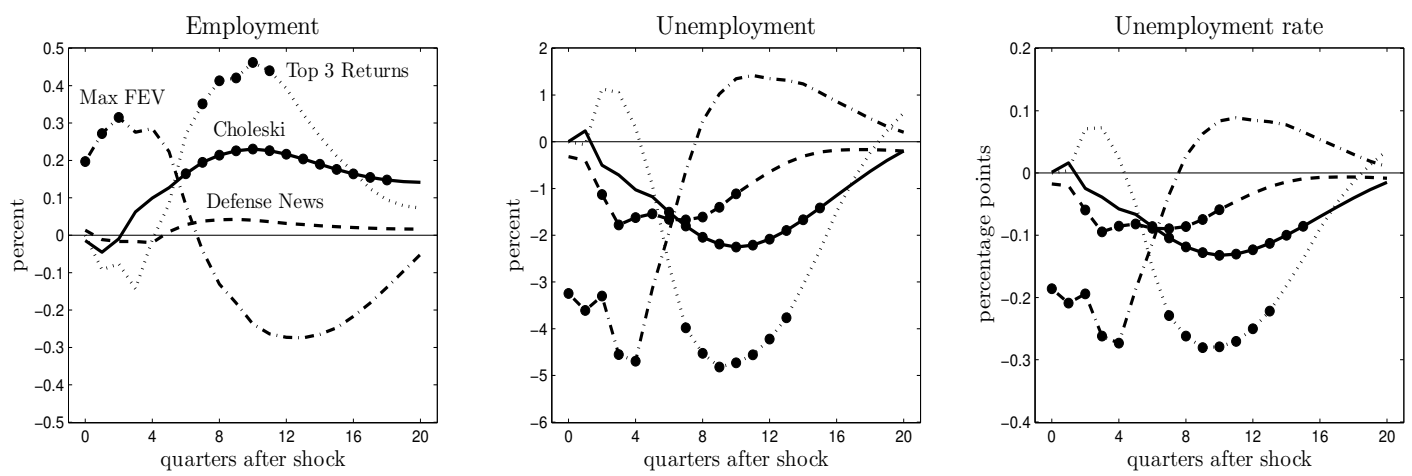

Fig. 1. Employment effects of a government spending shock

Notes: The figure plots VAR-based impulse responses to a government spending shock using four identification procedures: contemporaneous restrictions via the Choleski decomposition (solid lines), innovations to the Ramey (2011a) defense news series (dashed lines), innovations to the Fisher and Peters (2010) "Top 3" excess returns data (dotted lines), and the Ben Zeev and Pappa (2017) maximum forecast error variance methodology (dash-dotted lines). Bullets indicate point estimates that are significantly different from zero at a 90 -percent confidence level.

carried out in the context of a vector autoregression (VAR) estimated on quarterly U.S. data. But because there is no consensus on how best to achieve identification, I report estimates from a few different specifications. One imposes contemporaneous restrictions in the spirit of Blanchard and Perotti (2002). Another uses the narrative approach as implemented in Ramey (2011a). The next follows Fisher and Peters (2010) in identifying spending shocks as innovations to the excess stock returns of military contractors. The last model incorporates historical shocks recovered by Ben Zeev and Pappa (2017) that maximize contributions to the forecast error variance of defense spending over a five-year horizon.

Figure 1 graphs impulse responses for the logs of total civilian employment and unemployment (both divided by the population) as well as the unemployment rate. For each regression, the initial shock is normalized so that growth in per capita government consumption expenditures (not shown) reaches one percent at its peak. ${ }^{3}$ Results confirm that spending shocks increase the size of the working population and, at the same time, reduce the number of people who are unemployed. In all but one case, the change in the composition of the labor force is statistically significant at a 90 -percent confidence level. ${ }^{4} \mathrm{~A}$ similar pattern emerges for the unemployment rate, computed here as the log difference between total unemployment and the civilian labor force. Depending on identification, this ratio falls

\footnotetext{
${ }^{3}$ The Appendix provides details on the list of variables, lag structure, sample period, and identification strategy for each VAR. Also included is a description of the method used for obtaining confidence bands.

${ }^{4}$ Only when spending shocks are identified as innovations to the Ramey (2011a) defense news variable is the observed increase in employment not statistically significant.
} 
Table 1

Survey data estimates of the average consumption drop at unemployment

\begin{tabular}{|c|c|c|c|c|}
\hline study & sample period & data source & category & loss $(\%)$ \\
\hline Burgess, Kingston, St. Louis, and Sloane (1981) & $1975-1978$ & ABAS & total & 15.2 \\
\hline Gruber (1997) & $1968-1987$ & PSID & food & 6.8 \\
\hline Dynarski, Gruber, Moffitt, and Burtless (1997) & $1980-1993$ & CEX & total & 24.1 \\
\hline Stephens (2001) & $1968-1992$ & PSID & food & 8.5 \\
\hline Browning and Crossley (2001) & $1993-1995$ & COEP & total & 14.0 \\
\hline Stephens (2004) & $1992-1996$ & HRS & food & 16.0 \\
\hline Aguiar and Hurst (2005) & $1989-1996$ & CSFII & food & 19.0 \\
\hline Chetty and Szeidl (2007) & $1968-1997$ & PSID & food & 6.6 \\
\hline East and Kuka (2015) & $1968-2011$ & PSID & food & 7.0 \\
\hline Kroft and Notowidigdo (2016) & $1968-1997$ & PSID & food & 6.9 \\
\hline Chodorow-Reich and Karabarbounis (2016) & $1983-2012$ & CEX & total & 20.7 \\
\hline Hendren (2017) & $1992-2013$ & PSID & food & 7.0 \\
\hline Ganong and Noel (2019) & $2014-2016$ & JPMCI & food & 6.2 \\
\hline
\end{tabular}

Notes: ABAS - Arizona Benefit Adequacy Study; PSID - University of Michigan Panel Study of Income Dynamics; CEX Consumer Expenditure Survey of the Bureau of Labor Statistics; COEP - Canadian Out of Employment Panel of Human Resources Development Canada; HRS - University of Michigan Health and Retirement Study; CSFII - Continuing Survey of Food Intake of Individuals of the Department of Agriculture; JPMCI - JPMorgan Chase Institute de-identified account data.

anywhere from 0.1 to 0.3 percentage points in the first few years after a spending increase.

Equally important to the model is the idea that consumption temporarily decline for individuals who become unemployed. Assessing the validity of this dynamic, however, is complicated by the fact that standard measures of aggregate spending aren't broken down demographically by labor force status. To get around this problem, I look to papers from the micro literature on the household-level consumption effects of involuntary job loss. Table 1 displays a number of published estimates along with the data sources, sample periods, and spending categories for each. While results vary from one study to the next, the data generally agree on what matters most. The typical U.S. worker does not appear to be fully insured against employment risk. Just taking a simple average across the estimates points to a consumption drop at unemployment of around 12 percent. For the subset that use a measure of total expenditure (rather than food), the mean is actually closer to 18 percent.

Although survey data reject the full insurance hypothesis, any estimate of the consumption drop, if inserted into the model, would be too small to produce multipliers on the high side of the plausible range. To reach these levels while respecting the boundaries of Table 1 requires incorporating other mechanisms capable of transmitting fiscal shocks. I take up this task in the final section by adding to the efficiency-wage apparatus variable capital utilization along with Edgeworth complementarity between private and public consumption. Simulations reveal that large multipliers can be reconciled with the micro evidence on partial insurance without undermining the dominant role of the composition effect. This extended 
version of the model also yields credible predictions regarding the quantitative effects of two contemporary stimulus programs, namely, the American Recovery and Reinvestment Act of 2009 and the multi-year interest rate peg that was put in place soon thereafter.

\section{A Simple Model with Fixed Capital}

In this section I present an efficiency-wage model similar to Alexopoulos (2004). It is simple enough to work out analytical solutions showing the exact relationship between government spending multipliers and the amount of unemployment insurance held by individuals.

\subsection{A Flexible Price Benchmark}

I begin by deriving multipliers for output and private consumption in a version of the model with flexible prices. Abstracting from nominal rigidities makes it easier to sort out the role of incomplete insurance in the transmission of government spending shocks.

\section{A. The Model}

Families. There is a representative family with a $[0,1]$ continuum of members. In any period a random fraction $N_{t}$ get job offers. The other $1-N_{t}$ are unemployed. To preserve the representative agent framework with positive unemployment, I assume the family owns all the assets and makes all saving decisions.

The family enters date $t$ with capital $\bar{K}$ and one-period riskless government bonds worth $r_{t-1} b_{t-1}$, where $r_{t-1}$ is the gross real return from $t-1$ to $t$. It then leases $\bar{K}$ to firms at a rate of $r_{t}^{k}$ per unit, pays taxes $T_{t}$ to the government, and buys new bonds $b_{t}$. At the end of the period, any leftover resources are used to purchase consumption goods $C_{t}^{f}$ for each member. The budget constraint implied by this arrangement is

$$
C_{t}^{f}+b_{t} \leq r_{t-1} b_{t-1}+r_{t}^{k} \bar{K}-T_{t}
$$

Family members can increase their consumption by working. Firms offer job contracts that specify a fixed number of hours $h$ and an effort level $e_{t}$ for an hourly real wage $w_{t}$. But because effort cannot be perfectly observed, employees have an incentive to shirk. As in Alexopoulos (2004), I assume workers are paid a fraction $s$ of their wages up front. The 
final installment $(1-s) h w_{t}$ is paid out at the end of the period if shirking goes undetected. ${ }^{5}$ Shirkers are caught with probability $d \in(0,1)$.

To spread the risk of unemployment, the family manages an insurance program for its members. Each period workers contribute $F_{t}$ units of consumption into a pool that is redistributed equally to the unemployed. Let $C_{t}^{e}$ be the consumption of those not punished for shirking. Detected shirkers and unemployed members consume $C_{t}^{s}$ and $C_{t}^{u}$. It follows that

$$
\begin{aligned}
C_{t}^{e} & =C_{t}^{f}+h w_{t}-F_{t}, \\
C_{t}^{s} & =C_{t}^{f}+s h w_{t}-F_{t}, \\
C_{t}^{u} & =C_{t}^{f}+N_{t} F_{t} /\left(1-N_{t}\right) .
\end{aligned}
$$

The insurance program allows for a continuum of risk-sharing options. Specifically, $F_{t} \equiv$ $\sigma\left(1-N_{t}\right) h w_{t}$, where $\sigma \in[0,1]$ determines the replacement rate. Full insurance corresponds to $\sigma=1$ since $C_{t}^{e}=C_{t}^{u}$ in this case. When $0<\sigma<1$, the family only partially insures workers against job loss, allowing $C_{t}^{u}<C_{t}^{e}$ in equilibrium. ${ }^{6}$

The utility function of a family member $j$ with consumption $C_{t}^{j}$ is

$$
U\left(C_{t}^{j}, e_{t}\right)=\ln C_{t}^{j}+\theta \ln \left(H-\nu_{t}\left[h e_{t}+\xi\right]\right)
$$

where $\theta>0, H$ is the time endowment, and $\xi$ represents fixed costs of supplying effort. The function $\nu_{t}$ equals one if employed and exerting effort but zero otherwise.

The inability to monitor effort leads to moral hazard in the labor market. Alexopoulos (2006) shows that workers will uphold their end of the bargain as long as the terms of employment satisfy an incentive compatibility constraint

$$
U\left(C_{t}^{e}, e_{t}\right) \geq d U\left(C_{t}^{s}, 0\right)+(1-d) U\left(C_{t}^{e}, 0\right)
$$

The right-hand-side reveals that members who elect to shirk always choose to provide zero effort. This happens because the wage penalty is the same for any effort level below $e_{t}$, and utility is strictly decreasing in effort.

The family maximizes the present value of the average utility of its members, weighted by the employment probability of each type. But because they produce no output, it will

\footnotetext{
${ }^{5}$ Evidence suggests that firms often punish shirkers by withholding bonuses or denying promotions rather than termination. See Alexopoulos (2007) and references therein.

${ }^{6}$ As $\sigma$ increases, so does the incentive to lie about not having received an offer. To prevent voluntary unemployment, I assume the family sees which members receive offers and denies benefits to any who reject.
} 
never be profitable to hire shirkers. This means average utility can be written as

$$
E_{0} \sum_{t=0}^{\infty} \beta^{t}\left\{N_{t} U\left(C_{t}^{e}, e_{t}\right)+\left(1-N_{t}\right) U\left(C_{t}^{u}, 0\right)\right\}
$$

where $\beta \in(0,1)$ is the discount factor. Formally, sequences $\left\{C_{t}^{f}, b_{t}\right\}_{t=0}^{\infty}$ are chosen to maximize (6) subject to (1), (2), and (4). The Euler equations are given by

$$
\begin{aligned}
& \lambda_{t}=N_{t} / C_{t}^{e}+\left(1-N_{t}\right) / C_{t}^{u}, \\
& \lambda_{t}=\beta E_{t} \lambda_{t+1} r_{t} .
\end{aligned}
$$

The multiplier $\lambda_{t}$ equals the average marginal utility of consumption across members.

Firms. A $[0,1]$ continuum of firms produce homogeneous goods $y_{t}(i)$ according to

$$
y_{t}(i)=k_{t}(i)^{\alpha}\left[\left(n_{t}(i)-n_{t}^{s}(i)\right) e_{t}(i) h\right]^{1-\alpha},
$$

with $\alpha \in(0,1)$. Inputs $\left\{k_{t}(i), n_{t}(i), n_{t}^{s}(i), e_{t}(i)\right\}$ denote capital services, number of workers, shirkers, and effort levels employed by firm $i$. Because it wants to prevent shirking, the firm designs labor contracts that satisfy $(5)$, ensuring $n_{t}^{s}(i)=0$ in equilibrium. It follows that profit maximization can be expressed as

$$
\max _{\left\{k_{t}(i), n_{t}(i), w_{t}(i), e_{t}(i)\right\}} k_{t}(i)^{\alpha}\left(n_{t}(i) e_{t}(i) h\right)^{1-\alpha}-r_{t}^{k} k_{t}(i)-w_{t}(i) h n_{t}(i)
$$

subject to (5), which holds with equality since the firm wishes to compensate employees no more than what is required to induce effort. A binding incentive compatibility constraint implies that effort can be written in terms of the real wage as

$$
e_{t}(i)=\frac{H-\xi}{h}-\frac{H}{h}\left(\frac{C_{t}^{f}+h w_{t}(i)-F_{t}}{C_{t}^{f}+s h w_{t}(i)-F_{t}}\right)^{-d / \theta} \equiv e\left(w_{t}(i) ; C_{t}^{f}, F_{t}\right)
$$


Using (7) in place of $e_{t}(i)$ and taking $\left\{r_{t}^{k}, C_{t}^{f}, F_{t}\right\}$ as given, the first-order conditions are

$$
\begin{aligned}
r_{t}^{k} & =\alpha\left(\frac{y_{t}(i)}{k_{t}(i)}\right), \\
w_{t}(i) h & =(1-\alpha)\left(\frac{y_{t}(i)}{n_{t}(i)}\right), \\
\frac{e^{\prime}\left(w_{t}(i)\right) w_{t}(i)}{e\left(w_{t}(i)\right)} & =1 .
\end{aligned}
$$

The first two require that firms set the marginal products of capital and labor equal to the factor prices. Equation (8) is the classic Solow (1979) condition directing firms to administer an efficiency wage that minimizes labor costs per unit of effort. This quantity exceeds the Walrasian market-clearing wage, leading to positive unemployment in equilibrium.

As shown by Alexopoulos (2004), one implication of (8) is that the consumption ratio $C_{t}^{e} / C_{t}^{s}$ is constant and determined implicitly by

$$
H\left(\frac{d}{\theta}\right)(1-s \tilde{C})(\tilde{C}-1)=(1-s)\left[(H-\xi) \tilde{C}^{1+d / \theta}-H \tilde{C}\right]
$$

with $\tilde{C} \equiv C_{t}^{e} / C_{t}^{s}$. Inserting this ratio into (7) reveals that effort is also fixed over time, as

$$
e_{t}(i)=\frac{H-\xi}{h}-\frac{H}{h} \tilde{C}^{-d / \theta} \equiv e
$$

With constant effort, real wages are identical across firms, so $w_{t}(i)=w_{t}$ for all $i \in[0,1]$.

No-shirking condition. In efficiency-wage models of the moral hazard variety, the labor market is characterized by a no-shirking condition derived from workers' incentive compatibility constraint. This condition replaces the neoclassical labor supply curve seen in most business cycle models. Using $(2),(3)$, and $C_{t}^{e} / C_{t}^{s}=\tilde{C}$, the no-shirking condition can be expressed as

$$
h w_{t}=\frac{1}{1-s}\left(\frac{\tilde{C}-1}{\tilde{C}}\right) C_{t}^{e} .
$$

The incentive compatibility requirement also implies a constant ratio between the consumption of employed and unemployed workers. Combining (2) and (4) while substituting 
for $w_{t}$ using (10) yields

$$
\frac{C_{t}^{u}}{C_{t}^{e}}=1-\frac{1-\sigma}{1-s}\left(\frac{\tilde{C}-1}{\tilde{C}}\right) \equiv \mu(\sigma) .
$$

The function $\mu$ is bounded above by one and increasing in $\sigma$. So for a given $s$ and $\tilde{C}$, the value of $\mu$ defines the scope of insurance. With full insurance, $\mu(\sigma=1)=1$, and (11) reduces to $C_{t}^{u}=C_{t}^{e}$. With partial insurance, $\mu(\sigma<1)<1$, and (11) becomes $C_{t}^{u}=\mu C_{t}^{e}$.

Fiscal policy. Every period the government consumes $G_{t}$ units of the economy's final good, which it finances by collecting lump-sum taxes $T_{t}$. With the net supply of bonds equal to zero, the government's budget constraint is simply $G_{t}=T_{t}$.

I assume that government spending evolves exogenously according to

$$
G_{t}=(1-\rho) G+\rho G_{t-1}+\varepsilon_{t}
$$

where $\rho \in(0,1)$ and $\varepsilon_{t}$ is a mean-zero i.i.d. shock with constant variance.

Equilibrium. All market-clearing conditions must be satisfied in a competitive equilibrium. Balancing supply and demand for capital and labor means $\int_{0}^{1} k_{t}(i) d i \equiv \bar{K}$ and $\int_{0}^{1} n_{t}(i) d i \equiv N_{t}$ for $t \geq 0$. In product markets the supply of final goods, $\int_{0}^{1} y_{t}(i) d i \equiv Y_{t}$, must balance the demand from private and public consumption, so that

$$
Y_{t}=C_{t}+G_{t}
$$

each period. The term $C_{t}$ refers to aggregate private consumption and is defined as

$$
C_{t} \equiv N_{t} C_{t}^{e}+\left(1-N_{t}\right) C_{t}^{u}
$$

the sum total of the consumption levels of employed and unemployed family members.

\section{B. Government Spending Multipliers}

I measure the effects of an unanticipated increase in government purchases using the familiar impact multiplier. With capital fixed, quantities for both output and consumption can be derived analytically. In discussing the results, I focus on the range of insurance options needed to guarantee a positive consumption multiplier and thus an output multiplier in excess of one. 
PROPOSITION 1: In the shirking model with fixed capital and flexible prices,

(i) the impact multipliers for output and consumption are given by

$$
\frac{d Y_{t}}{d G_{t}} \equiv \Gamma_{y}=\left[1+\frac{1-g}{1-\alpha}\left(\alpha-\frac{(1-\mu) N}{(1-\mu) N+\mu}\right)\right]^{-1} \quad \frac{d C_{t}}{d G_{t}} \equiv \Gamma_{c}=\Gamma_{y}-1,
$$

(ii) $\Gamma_{y}$ and $\Gamma_{c}$ are strictly decreasing functions of $\mu$, and

(iii) $\Gamma_{y}>1$ and $\Gamma_{c}>0$ if and only if

$$
\alpha<\frac{(1-\mu) N}{(1-\mu) N+\mu} \quad \Leftrightarrow \quad \mu<\frac{(1-\alpha) N}{(1-\alpha) N+\alpha} \equiv \mu_{1}
$$

\section{PROOF:}

See Appendix.

Part one shows that the multipliers, denoted $\Gamma_{y}$ and $\Gamma_{c}$, are determined by four factors. Two of those factors, $N$ and $g$, are the steady-state levels of employment and the share of government spending in output (i.e., $G / Y$ ). The other two are the capital income share $\alpha$ and the degree of unemployment insurance $\mu$.

The second part demonstrates that $\Gamma_{y}$ and $\Gamma_{c}$ are decreasing in the insurance coefficient. So as $\mu$ gets smaller, or as risk sharing among family members declines, the expansionary effects of a shock to government spending get bigger. By how much depends on the size of the other parameters. Figure 2 plots $\Gamma_{y}$ (solid line) and $\Gamma_{c}$ (dashed line) as functions of $\mu$, holding fixed the values of $N, g$, and $\alpha .^{7}$ In the case of full insurance $(\mu=1)$, consumption is negative and output less than one. But as unemployment insurance drops, the multipliers begin to rise at an increasing rate. For small enough values of $\mu$, spending shocks "crowd-in" private consumption, ensuring an output multiplier greater than one. In the extreme case of zero insurance, for which $\mu(0)=0.19, \Gamma_{y}$ reaches a maximum of 2.41 .

Part three of the proposition identifies the critical value of $\mu$, call it $\mu_{1}$, for which $\Gamma_{c}=0$ and $\Gamma_{y}=1$. In the figure $\mu_{1}$ is about 0.65. At this level of risk sharing, consumption falls by 35 percent for members who become unemployed. Of course any value below $\mu_{1}$, given part $(i i)$, is consistent with $\Gamma_{c}>0$ and $\Gamma_{y}>1$.

This last finding is notable because it goes against the neoclassical view of fiscal policy. As shown by Woodford (2011), government purchases necessarily crowd out private consumption

\footnotetext{
${ }^{7}$ Values of $N$ and $g$ are chosen to match the average civilian employment rate and the ratio of government consumption expenditures to GDP in the U.S. from 1948 to 2018.
} 


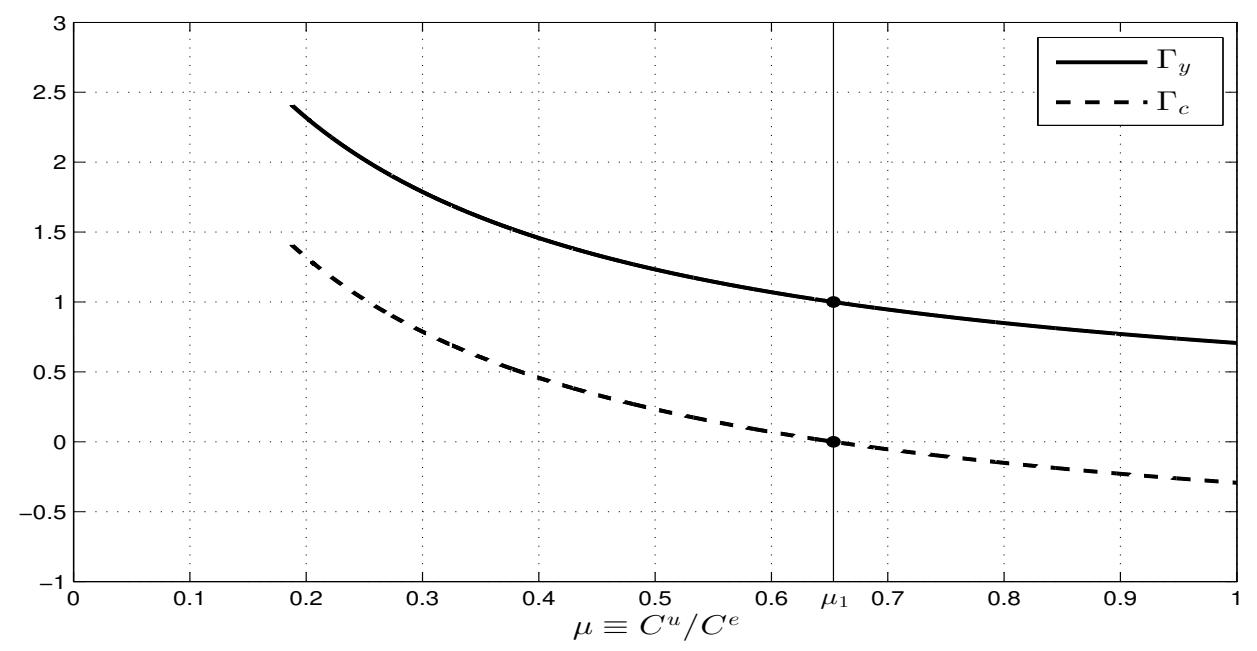

Fig. 2. Impact multipliers: flexible prices

Notes: Impact multipliers for output $\left(\Gamma_{y}\right)$ and consumption $\left(\Gamma_{c}\right)$ are shown as functions of the insurance coefficient $\mu$. Computations are based on the following calibration: $g=0.17, N=0.942, \alpha=1 / 3$.

in standard optimizing models with flexible prices and wages. Indeed if one were to replace the labor market described above with a purely neoclassical structure, the multipliers for output $\left(\tilde{\Gamma}_{y}\right)$ and consumption $\left(\tilde{\Gamma}_{c}\right)$ would be

$$
\tilde{\Gamma}_{y}=\left[1+\frac{1-g}{1-\alpha}(\alpha+\varphi)\right]^{-1} \quad \text { and } \quad \tilde{\Gamma}_{c}=\tilde{\Gamma}_{y}-1
$$

where $1 / \varphi \geq 0$ is the Frisch labor supply elasticity. ${ }^{8}$ Clearly $\tilde{\Gamma}_{y} \in(0,1)$ and $\tilde{\Gamma}_{c}<0$ for any permissable value of $\varphi$. And should labor supply be inelastic, $\tilde{\Gamma}_{y}$ may be close to zero.

Now the reasons why multiplier effects are mostly absent in the neoclassical model are well known (e.g., Aiyagari, Christiano, and Eichenbaum, 1992; Baxter and King, 1993). The goal of this paper is not to rehash these old arguments, but rather to explain how the introduction of unemployment and partial insurance alters the conventional narrative. As a starting point, I rewrite $d C_{t} / d G_{t}$ as the sum of its intensive and extensive margin adjustments. The former refers to changes in the consumption of individual members and, as explained below, is heavily influenced by the usual wealth effects of government spending. The latter describes movements in the size of the working population, what I henceforth call the composition effect. The math is easy. Just differentiate (12) with respect to $G_{t}$ and

\footnotetext{
${ }^{8} \tilde{\Gamma}_{y}$ and $\tilde{\Gamma}_{c}$, are derived from a one-sector business cycle model with divisible labor, constant-returns-toscale production, and preferences of the form $\ln C+\theta \frac{h^{1+\varphi}}{1+\varphi}$.
} 
collect terms. The result when evaluated at the steady state is

$$
\frac{d C_{t}}{d G_{t}}=\underbrace{N \frac{d C_{t}^{e}}{d G_{t}}+(1-N) \frac{d C_{t}^{u}}{d G_{t}}}_{\text {intensive margin }(<0)}+\underbrace{(1-\mu) C^{e} \frac{d N_{t}}{d G_{t}}}_{\text {extensive margin }(\geq 0)}
$$

The first bracketed term captures the effect on $C_{t}$ of changes in individual consumption triggered by a decline in family wealth. It is similar, but not identical to, the effect that runs through the neoclassical analysis. Here an increase in government spending (taxes) tightens the budget constraint (1), prompting an immediate withdrawal of family consumption $C_{t}^{f}$. As explained in Alexopoulos (2004), this pushes up the ratio $C_{t}^{e} / C_{t}^{s}$, which effectively increases the penalty associated with shirking. Now employees will strictly prefer effort. To make workers indifferent between the two, firms scale back the real wage until $C_{t}^{e} / C_{t}^{s}=\tilde{C}$ is restored, or until the incentive compatibility constraint re-balances. Facing cuts to both wages and family consumption, employed and unemployed workers alike have to reduce $C_{t}^{e}$ and $C_{t}^{u}$. This crowding out of individual consumption, assuming for the moment no change in employment, forces aggregate consumption lower.

Obviously employment will not remain constant for long. As wages go down, firms have an incentive to hire more workers. This results in a larger share of the family consuming $C_{t}^{e}$ and a smaller share consuming $C_{t}^{u}$. What the second bracketed term captures is the effect on $C_{t}$ of this shift in the composition of the workforce between employed and unemployed members. Under full insurance $(\mu=1)$, the effect vanishes since consumption is the same for everyone. But if $\mu<1$, or $C_{t}^{u}<C_{t}^{e}$, rising employment drives up aggregate consumption even as individual consumption levels fall. Should the degree of insurance be sufficiently small $\left(\mu \leq \mu_{1}\right)$, the composition effect will dominate, and aggregate consumption will respond positively to an increase in government purchases.

\section{The Labor Market}

The previous section identifies the composition effect as the mechanism responsible for any increase in consumption. Yet the analysis is insufficient because it fails to explain why the effect can be large enough to offset the crowding out of individual consumption. To address this shortcoming, I take a closer look at how the insurance arrangement affects key properties of the no-shirking condition, which serves as the appropriate labor supply concept in the model. I also discuss the findings in relation to a different transmission mechanism that turns out to have similar reduced-form implications. 
My focus on the labor market is motivated by recent analyses of government spending in Linnemann (2006), Bilbiie (2009), and Bilbiie (2011). Each demonstrates that an increase in consumption is attainable in a one-sector model with flexible prices if and only if the constantconsumption labor supply curve is both downward sloping and steeper than labor demand. To be clear, what gives the supply curve its unusual shape is the use of a nonseparable preference structure that makes consumption and work hours Edgeworth complements. But as Bilbiie (2009) rightly points out, the conditions required for this result violate strict concavity of the utility function, a feature he argues should be avoided in business cycle models because it implies that consumption will be an inferior good.

An advantage of the present model is that it yields the same reduced-form description of the labor market while preserving standard assumptions on preferences (i.e., log separability). This result is made possible by the fact that the relevant wage-employment locus characterizing the supply side of the market is the constant-consumption no-shirking condition. As discussed earlier, this condition replaces the ordinary neoclassical relationship linking the real wage to the marginal rate of substitution. But unlike the latter, it will be negatively sloped should one relax the traditional assumption of full insurance.

To develop this point, I log-linearize the no-shirking equation (10) along with the risksharing condition (11) and the aggregate consumption identity (12). Substituting all three into a single expression produces a constant-consumption no-shirking condition

$$
\hat{w}_{t}=-\frac{(1-\mu) N}{(1-\mu) N+\mu} \hat{N}_{t}+\hat{C}_{t}
$$

where hatted variables denote percentage deviations from the nonstochastic steady state. ${ }^{9}$

Clearly the insurance coefficient $\mu$ affects the slope of (13). With full insurance the slope is zero, and employment variations have no effect on the incentive-compatible real wage. But under partial insurance, it is both negative and increasing in $\mu$, meaning the curve gets steeper (more negative) as unemployment benefits shrink. To understand why this inversion occurs, recall that an increase in employment reduces the average marginal utility of consumption since utility is concave and $C_{t}^{e}>C_{t}^{u}$. Re-balancing marginal utility with the shadow value of wealth requires lowering individual consumption through cutbacks in the real wage. Exactly how far wages must fall for a given increase in employment depends on the initial drop in average marginal utility. This magnitude will be bigger when consumption inequality is high, or when unemployment insurance is low.

\footnotetext{
${ }^{9}$ For any variable $X_{t}$ with steady state $X$, let $\hat{X}_{t} \equiv \ln X_{t}-\ln X$.
} 


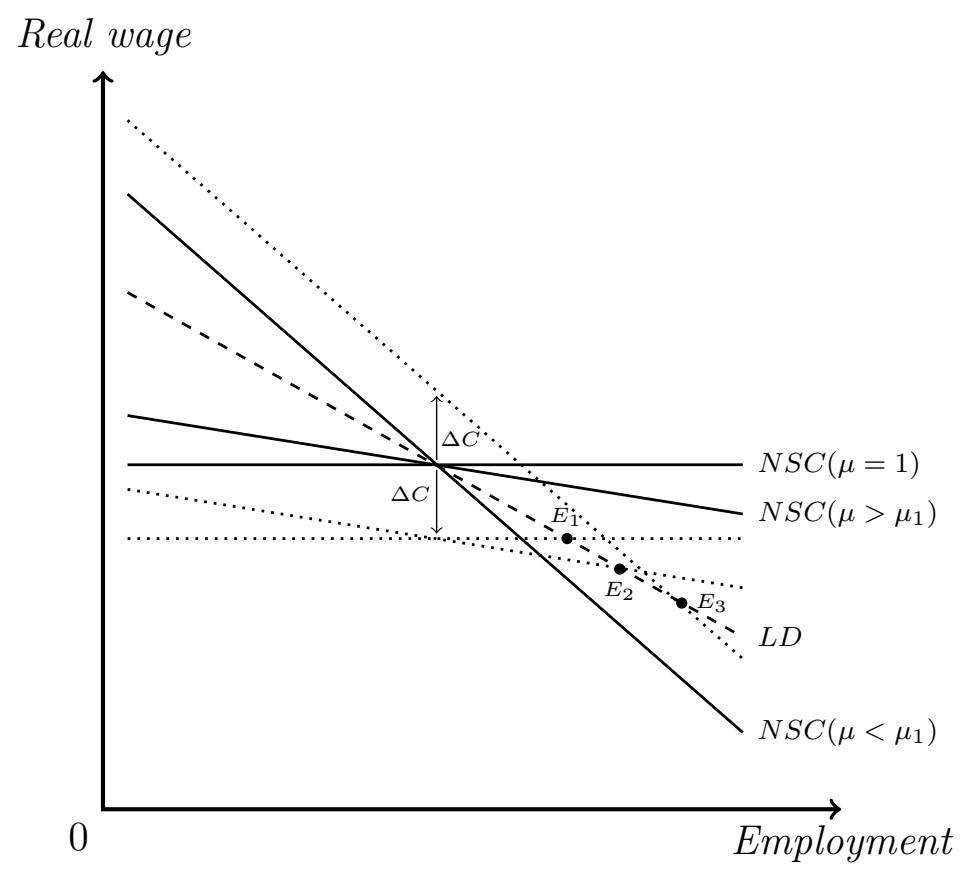

Fig. 3. Labor market equilibrium

Notes: The diagram illustrates the labor market effects of an increase in government spending under $(i)$ full insurance $(\mu=1)$, (ii) partial insurance with $\mu>\mu_{1}$, and (iii) partial insurance with $\mu<\mu_{1}$. Equilibrium occurs at the intersection of labor demand $(L D)$ and the constant-consumption no-shirking condition $(N S C)$. In each case the increase in government spending shifts the $N S C$ by an amount equal to the eventual change in aggregate consumption $(\Delta C)$.

Holding aggregate consumption constant, equation (13) and the log-linearized demand schedule, $\hat{w}_{t}=-\alpha \hat{N}_{t}$, jointly determine the equilibrium real wage and employment levels. Both curves will be negatively sloped absent full insurance. What's more, if the degree of insurance is small enough, the no-shirking condition will be steeper than labor demand in a manner isomorphic to Bilbiie (2011) and others. It should come as no surprise then that values of $\mu$ satisfying $\alpha<(1-\mu) N /[(1-\mu) N+\mu]$ are precisely the same values under Proposition 1 that give $\Gamma_{c}>0$ and $\Gamma_{y}>1$.

Figure 3 depicts the situation in the labor market under $(i)$ full insurance, (ii) partial insurance with $\mu>\mu_{1}$, and (iii) partial insurance with $\mu<\mu_{1}$. Equilibrium occurs where labor demand $(L D)$ intersects the no-shirking condition $(N S C)$. As for $(i)$ and $(i i)$, an increase in government spending has no effect on demand but shifts down the no-shirking condition since the policy ultimately reduces aggregate consumption. Notice that for a given drop in consumption, the increase in employment is greater under partial insurance $\left(E_{2}\right)$ than under full insurance $\left(E_{1}\right)$. Though in neither case is the expansion large enough to generate an output multiplier bigger than one. Case (iii) is different. Now government 
spending lifts aggregate consumption, causing (13) to shift up instead. The ensuing increase in employment $\left(E_{3}\right)$ is sufficient to raise output by more than the spending shock.

\subsection{A Sticky Price Benchmark}

Incorporating sticky prices can, under certain conditions, enlarge the multiplier effects observed in neoclassical models of fiscal policy (e.g., Monacelli and Perotti, 2008; Hall, 2009). To see if similar results emerge in the shirking model, I re-derive the multipliers under the assumption of Calvo-Yun price stickiness in the goods market. In describing the model, I comment only on features that are different from the flexible price setup.

\section{A. The Model}

Families. The family buys riskless, one-period nominal government bonds. Denote $B_{t}$ the amount purchased at date $t$, and let $R_{t}$ be the gross interest rate from $t$ to $t+1$.

In addition to bonds, the family receives dividends $\int_{0}^{1} D_{t}(i) d i$ from ownership of intermediate good firms. These two income sources enter the budget constraint

$$
C_{t}^{f}+\frac{B_{t}}{P_{t}} \leq \frac{R_{t-1} B_{t-1}}{P_{t}}+r_{t}^{k} \bar{K}-T_{t}+\frac{1}{P_{t}} \int_{0}^{1} D_{t}(i) d i
$$

where $P_{t}$ is the unit price of the economy's finished good.

Finished good firms. A competitive firm produces finished goods $Y_{t}$ by assembling a continuum of intermediate goods $\left\{y_{t}(i)\right\}$ using the Dixit-Stiglitz aggregator $Y_{t}^{1-1 / \eta}=\int_{0}^{1} y_{t}(i)^{1-1 / \eta} d i$. Its derived demand for good $i$ takes the form

$$
y_{t}(i)=\left(\frac{P_{t}(i)}{P_{t}}\right)^{-\eta} Y_{t}
$$

where $P_{t}(i)$ is the unit price of $y_{t}(i)$ and $\eta>1$ is the substitution elasticity across varieties. The zero-profit condition ensures that the finished good price satisfies $P_{t}^{1-\eta}=\int_{0}^{1} P_{t}(i)^{1-\eta} d i$.

Intermediate good firms. A $[0,1]$ continuum of firms manufacture the economy's intermediate goods. Each period firm $i$ selects $\left\{k_{t}(i), n_{t}(i), w_{t}(i), e_{t}(i)\right\}$ to minimize unit production costs subject to the incentive compatibility condition (5). Constant returns guarantee that real 
marginal cost is the same across firms and given by

$$
m c_{t}=\Phi\left(r_{t}^{k}\right)^{\alpha}\left(\frac{w_{t}}{e}\right)^{1-\alpha}
$$

where $\Phi \equiv \alpha^{-\alpha}(1-\alpha)^{\alpha-1}$ and $e$ is the optimal effort level in (9).

Although wages are renegotiated every period, prices may be fixed for several periods. Following Calvo (1983) and Yun (1996), a fraction $1-\chi$ of randomly selected firms adjust their prices optimally each period. The other $\chi$ firms keep their prices unchanged. A firm that chooses a new price $\tilde{P}_{t}$ solves

$$
\max _{\tilde{P}_{t}} E_{t} \sum_{j=0}^{\infty}(\chi \beta)^{j}\left(\frac{\lambda_{t+j} / P_{t+j}}{\lambda_{t} / P_{t}}\right)\left[\left(\frac{\tilde{P}_{t}}{P_{t+j}}-m c_{t+j}\right) P_{t+j}\left(\frac{\tilde{P}_{t}}{P_{t+j}}\right)^{-\eta} Y_{t+j}\right],
$$

where $\beta^{j}\left(\lambda_{t+j} / P_{t+j}\right) /\left(\lambda_{t} / P_{t}\right)$ measures the family's date- $t$ nominal value of profits accruing at $t+j$. Substituting the first-order condition into the finished good price index implied by the Calvo technology gives $\chi \pi_{t}^{\eta-1}+(1-\chi)\left(\tilde{P}_{t} / P_{t}\right)^{1-\eta}=1$, where $\pi_{t} \equiv P_{t} / P_{t-1}$.

Monetary policy. When prices are sticky, the effects of government spending depend on monetary policy. In this model the central bank sets the interest rate according to

$$
\ln R_{t}=\ln R+\phi_{\pi} \ln \pi_{t}
$$

where $R$ is the steady-state value of $R_{t}$ and the response coefficient $\phi_{\pi}>1 .^{10}$ The restriction on $\phi_{\pi}$ is both necessary and sufficient for equilibrium determinacy.

Equilibrium. The clearing of intermediate good markets requires that

$$
k_{t}(i)^{\alpha}\left(n_{t}(i) e h\right)^{1-\alpha}=\left(\frac{P_{t}(i)}{P_{t}}\right)^{-\eta} Y_{t} \quad \forall i \in[0,1]
$$

each period. Integrating (15) connects output, capital, and employment by

$$
\bar{K}^{\alpha}\left(N_{t} e h\right)^{1-\alpha}=\Delta_{t} Y_{t},
$$

where $\Delta_{t} \equiv \int_{0}^{1}\left(\frac{P_{t}(i)}{P_{t}}\right)^{-\eta} d i$ summarizes the resource cost of price dispersion.

\footnotetext{
${ }^{10}$ The nonstochastic steady state corresponds to the one with zero inflation.
} 


\section{B. Government Spending Multipliers}

Below I explain how the fiscal multipliers depend on unemployment insurance and if sticky prices alter this relationship vis-à-vis flexible prices.

PROPOSITION 2: In the shirking model with fixed capital and Calvo-Yun prices,

(i) the impact multipliers for output and consumption are given by

$$
\frac{d Y_{t}}{d G_{t}} \equiv \Sigma_{y}=\frac{(1-\rho)+\kappa\left(\frac{\phi_{\pi}-\rho}{1-\beta \rho}\right)}{(1-\rho)\left[1-\left(\frac{1-g}{1-\alpha}\right) f(\mu)\right]+\kappa\left(\frac{\phi_{\pi}-\rho}{1-\beta \rho}\right) \Gamma_{y}^{-1}} \quad \frac{d C_{t}}{d G_{t}} \equiv \Sigma_{c}=\Sigma_{y}-1
$$

where $\kappa \equiv \frac{(1-\chi)(1-\chi \beta)}{\chi}$ and $f(\mu) \equiv \frac{(1-\mu) N}{(1-\mu) N+\mu}-\frac{(1-\mu) N}{1-(1-\mu) N}<0$ for $N>\frac{1}{2}$,

(ii) $\Sigma_{y}>1$ and $\Sigma_{c}>0$ if and only if

$$
\alpha-f(\mu)\left(\frac{(1-\rho)(1-\beta \rho)}{\kappa\left(\phi_{\pi}-\rho\right)}\right)<\frac{(1-\mu) N}{(1-\mu) N+\mu} \text {, and }
$$

(iii) $\Sigma_{y}>\Gamma_{y}$ and $\Sigma_{c}>\Gamma_{c}$ if and only if

$$
\alpha>\frac{(1-\mu) N}{1-(1-\mu) N} \quad \Leftrightarrow \quad \mu>1-\frac{\alpha}{1+\alpha} \frac{1}{N} \equiv \mu^{*} .
$$

\section{PROOF:}

See Appendix.

The first part shows that the multipliers, denoted $\Sigma_{y}$ and $\Sigma_{c}$, are more complicated than their flexible-price counterparts. Each is itself a function of $\Gamma_{y}$ in addition to other common terms like the discount factor $\beta$ and the persistence of government spending $\rho$. Note also that $\Sigma_{y}$ and $\Sigma_{c}$ depend on two concepts unique to the sticky price model, the fraction of fixed-price firms $\chi$ and the monetary policy response coefficient $\phi_{\pi}$.

One implication of this added complexity is that the multipliers are no longer universally decreasing with respect to unemployment insurance. So there is no provable sticky-price analog to part two of Proposition 1. For typical parameter values though, $\Sigma_{y}$ and $\Sigma_{c}$ still increase as $\mu$ gets smaller, or as unemployment benefits decline. ${ }^{11}$ How elastic the relationship is can be seen in Figure 4, which graphs $\Sigma_{y}$ (solid line) and $\Sigma_{c}$ (dashed line) as functions of $\mu$. For the sake of comparison, the figure also shows $\Gamma_{y}$ and $\Gamma_{c}$.

\footnotetext{
${ }^{11}$ In the Appendix I derive conditions under which $\Sigma_{y}$ and $\Sigma_{c}$ will be strictly decreasing in $\mu$.
} 


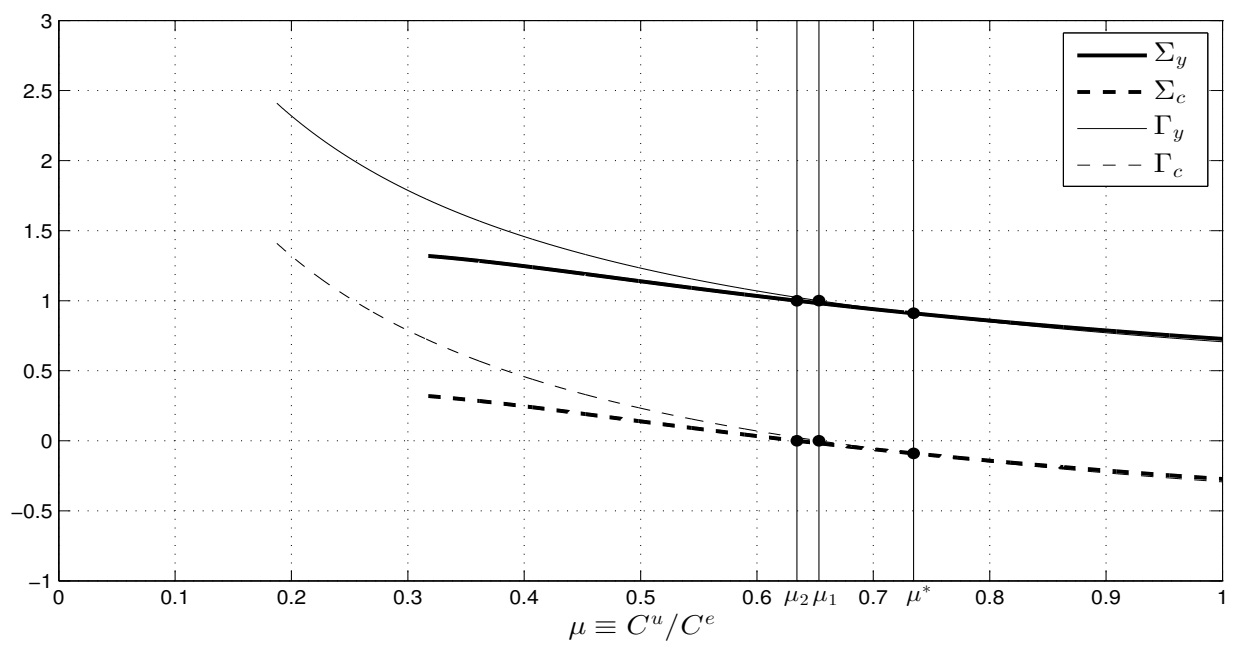

Fig. 4. Impact multipliers: sticky prices

Notes: Impact multipliers for output $\left(\Sigma_{y}\right)$ and consumption $\left(\Sigma_{c}\right)$ under sticky prices are shown as functions of the insurance coefficient $\mu$. Also shown are the multipliers for output $\left(\Gamma_{y}\right)$ and consumption $\left(\Gamma_{c}\right)$ under flexible prices. Computations are based on the following calibration: $\beta=0.99, g=0.17, \rho=0.90, N=0.942, \alpha=1 / 3, \chi=2 / 3, \eta=6, \phi_{\pi}=1.50$.

When unemployment insurance is high, flexible and sticky prices produce nearly identical results. Daylight between the two emerges only when the economy moves far away from full insurance, with $\Sigma_{y}$ and $\Sigma_{c}$ being smaller. The biggest gaps occur in the case of zero insurance, where $\mu(0)=0.32$. That this value is higher than the lower bound under flexible prices traces to the impact of profits on family consumption $C_{t}^{f}$.

Part two reasserts the central finding of the paper. A positive consumption multiplier and hence an output multiplier greater than one is still possible under sticky prices if unemployment insurance is low enough. The critical value of $\mu$, call it $\mu_{2}$, for which $\Sigma_{c}=0$ and $\Sigma_{y}=1$ is about 0.63 . This is slightly less than the value under flexible prices $\left(\mu_{1}\right)$ and implies a consumption drop of 37 percent for members who lose their job.

The mechanism behind this result is really no different than before. Rising employment pushes up aggregate consumption through a composition effect that offsets the drop in individual consumption induced by higher taxes. The only nuance concerns the exact degree of risk sharing at which the composition effect becomes the dominant force. Under flexible prices, the relevant sufficient condition was that the no-shirking equation (13) be steeper than labor demand (i.e., $(1-\mu) N /[(1-\mu) N+\mu]>\alpha)$. This same condition is necessary but no longer sufficient under sticky prices. Now $\mu$ must be small enough so that the slope of the no-shirking condition exceeds the slope of labor demand by an amount greater than 
or equal to $-f(\mu)(1-\rho)(1-\beta \rho) /\left[\kappa\left(\phi_{\pi}-\rho\right)\right]>0 .{ }^{12}$

A closer look at the labor market reveals why the insurance criteria is generally more restrictive under sticky prices. An increase in government spending shifts both the noshirking locus and the labor demand schedule simultaneously. However, for the range of insurance options consistent with $\Sigma_{y} \geq 1$, the shift in labor demand undermines some of the positive employment effects brought about by a lower incentive-compatible real wage.

To see how this dynamic plays out in the model, consider the log-linearized labor demand equation $\hat{w}_{t}=-\alpha \hat{N}_{t}+\hat{m} c_{t}$. At any given wage, employment demand depends positively on real marginal cost (or inversely on the markup). Whether marginal cost goes up or down after a fiscal shock though depends on the degree of unemployment insurance. In this case I find it helpful to look at the analytical solution

$$
\hat{m} c_{t}=\frac{g}{1-g}\left(\frac{\Sigma_{y}}{\Gamma_{y}}-1\right) \hat{G}_{t} .
$$

The key term here is $\Sigma_{y} / \Gamma_{y}$. When this ratio is below one, as it is for $\mu=\mu_{2}$, marginal cost falls (markups rise) after an increase in government spending. This reduces labor demand, which for a given wage, partially offsets the positive impetus on employment caused by firms' realignment of the incentive compatibility constraint (i.e., the outward shift in the no-shirking condition). Generating an output multiplier bigger than one therefore requires a smaller amount of insurance than the flexible price case. A lower value of $\mu$ effectively compensates for the offsetting labor demand effect under sticky prices.

By contrast, if marginal cost were to respond procyclically, the ensuing increase in labor demand would strengthen any positive employment effects originating from the supply side of the market. Impact multipliers in this case would be larger than the ones observed under flexible prices where labor demand remains fixed.

Part three of the proposition describes this scenario and identifies conditions on $\mu$ that make it possible. Evidently there is a critical value of $\mu$, call it $\mu^{*}$, for which $\Sigma_{y}=\Gamma_{y}$ and $\Sigma_{c}=\Gamma_{c}$. At this level of insurance there will be no reaction of marginal cost to a spending shock, no shift in labor demand, and therefore no difference in outcomes between the two models. ${ }^{13}$ On the other hand, values above $\mu^{*}$ elicit a positive response of marginal cost,

\footnotetext{
${ }^{12}$ The critical value $\mu_{2}$ is defined implicitly by $\frac{\left(1-\mu_{2}\right) N}{\left(1-\mu_{2}\right) N+\mu_{2}}=\alpha-f\left(\mu_{2}\right)\left(\frac{(1-\rho)(1-\beta \rho)}{\kappa\left(\phi_{\pi}-\rho\right)}\right)$.

${ }^{13}$ The value $\mu^{*}$ corresponds exactly to the insurance level that equalizes the slopes of the labor demand curve and the "Frisch" no-shirking condition (e.g., Nakajima, 2006). The latter describes the inverse relationship between employment and the incentive-compatible wage for a constant average marginal utility of wealth $\lambda_{t}$. Its slope is given by $-(1-\mu) N /[1-(1-\mu) N]$. See the Appendix for details.
} 
producing multipliers that exceed $\Gamma_{y}$ and $\Gamma_{c}$. But results show these gains to be negligible and present only at insurance levels that give $\Sigma_{c}<0$ and $\Sigma_{y}<1$.

\section{A Model with Capital Accumulation}

An obvious limitation of the preceding analysis is the invariance of the capital stock. As shown by Baxter and King (1993), opening the investment margin can have significant effects on the size of government spending multipliers. In this section I reexamine the policy consequences of unemployment insurance while allowing for capital accumulation.

One problem with extending the model along these lines is the emergence of indeterminacy. In a continuous-time version of the model, Nakajima (2006) proves that indeterminacies will occur if unemployment insurance falls below a certain threshold. What complicates matters here is that this boundary turns out to be above the point at which positive consumption multipliers show up in the benchmark model. Should Nakajima's result carry over to discrete time, the implication would be that any amount of insurance small enough to increase consumption after a spending shock will also lead to multiple equilibria.

With this in mind, I evaluate the multipliers under two different assumptions about capital accumulation. One is the standard textbook example in which a unit of investment at time $t$ is costlessly transformed into a unit of productive capital at $t+1$. While this assumption indeed rules out a large area of the insurance space as indeterminate, I find that output multipliers can still exceed one under partial insurance by virtue of a positive response of investment. In the second case, a share of the family's investment spending each period gets absorbed by adjustment costs. This feature dramatically shrinks the indeterminacy region, allowing scrutiny of a wider range of insurance options, including ones consistent with a positive consumption multiplier.

\section{A. The Model}

Augmenting the model with capital accumulation is straightforward. Most of the key components are unaffected by the presence of an investment channel. So in my discussion, I reserve space only for those pieces that depart from the benchmark setup.

Families. Let $K_{t}$ denote the period- $t$ stock of capital. Rental income $r_{t}^{k} K_{t}$ along with dividend and bond wealth is used for purchasing new bond holdings $B_{t}$, family consumption 
$C_{t}^{f}$, and investment goods $I_{t}$. It follows that the budget constraint takes the form

$$
C_{t}^{f}+I_{t}+\frac{B_{t}}{P_{t}} \leq \frac{R_{t-1} B_{t-1}}{P_{t}}+r_{t}^{k} K_{t}-T_{t}+\frac{1}{P_{t}} \int_{0}^{1} D_{t}(i) d i
$$

The economy's finished good, again priced at $P_{t}$ per unit, can be either consumed or invested.

The law of motion for capital is given by

$$
K_{t+1}=(1-\delta) K_{t}+\phi\left(\frac{I_{t}}{K_{t}}\right) K_{t}
$$

where the depreciation rate $\delta \in(0,1)$ and $\phi\left(I_{t} / K_{t}\right)$ is an adjustment cost function that determines how many units of capital are produced from investment spending $I_{t}$. Following Abel and Blanchard (1983), I assume $\phi^{\prime}>0$ and $\phi^{\prime \prime} \leq 0$, with $\phi(\delta)=\delta$ and $\phi^{\prime}(\delta)=1$. The cost function is assumed to be only weakly concave in order to accommodate the two cases described above. The first one assumes adjustment costs have no effect on investment dynamics and is obtained by restricting $\phi^{\prime \prime}=0$. The second relaxes this assumption by allowing $\phi^{\prime \prime}<0$. In choosing the size of adjustment costs, I copy King and Watson (1996) and Galí et al. (2007) by fixing $\phi^{\prime \prime}$ so that the model delivers a unitary elasticity of investment with respect to $q$ (i.e., the shadow value of installed capital). ${ }^{14}$

Equilibrium. For intermediate goods, integrating the market-clearing condition (15) gives

$$
K_{t}^{\alpha}\left(N_{t} e h\right)^{1-\alpha}=\Delta_{t} Y_{t}
$$

where $K_{t} \equiv \int_{0}^{1} k_{t}(i) d i$. For finished goods, balancing supply and demand each period requires

$$
Y_{t}=C_{t}+I_{t}+G_{t}
$$

\section{B. Indeterminacy and Government Spending Multipliers}

In this section I search for the set of insurance options that jointly satisfy (local) determinacy and a bigger-than-one output multiplier. Although analytical methods are available, the solutions are tedious and difficult to interpret. So from this point on, I rely on numerical solutions to the log-linearized equations of the model.

\footnotetext{
${ }^{14}$ The (steady-state) elasticity of the investment-capital ratio with respect to $q$ is given by $-1 / \delta \phi^{\prime \prime}(\delta)$.
} 

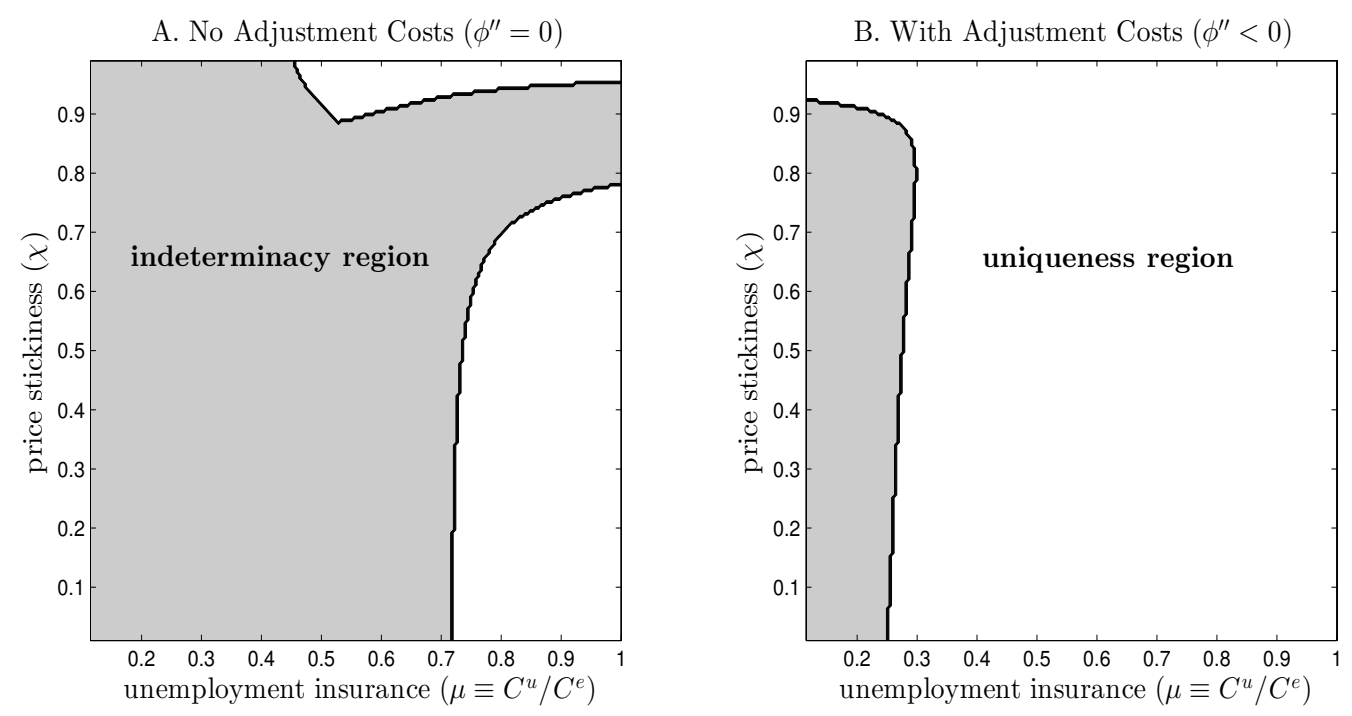

Fig. 5. Determinacy analysis

Notes: Regions of the parameter space $(\mu, \chi)$ consistent with a unique equilibrium (light area) or indeterminacy (dark area) are shown for the models without capital adjustment costs (A) and with adjustment costs included (B). Computations are based on the following calibration: $\beta=0.99, g=0.17, \rho=0.90, N=0.942, \alpha=1 / 3, \eta=6, \phi_{\pi}=1.50, \delta=0.025, \phi^{\prime \prime}(\delta)=\{0,-40\}$.

First consider the case without adjustment costs $\left(\phi^{\prime \prime}=0\right)$. Panel A of Figure 5 illustrates regions of the parameter space $(\mu, \chi)$ associated with equilibrium uniqueness or indeterminacy, holding the other parameters fixed at baseline values. As anticipated, capital accumulation renders much of the insurance space indeterminate. And this is true regardless of the mass of fixed-price firms in the economy. Under flexible prices $(\chi=0)$, indeterminacy arises whenever $\mu<0.72$, which is close to the threshold value reported in Nakajima (2006). Under sticky prices, the threshold is generally higher and increasing in $\chi$. The only exceptions are cases in which price stickiness is unusually large. Regarding questions of fiscal policy, the main takeaway is that insurance levels found earlier to be consistent with positive consumption multipliers lead to indeterminacy in the present model for any plausible value of $\chi$. It is also worth noting that multiple equilibria abound even though the interest rate rule (14) satisfies the well-known Taylor principle, expressed here as $\phi_{\pi}>1$. In a broad class of sticky price models, adherence to the Taylor principle is often cited as a sufficient condition for determinacy (e.g., Woodford, 2003).

Figure 6 plots impact multipliers for output, consumption, and investment over admissible vales of $\mu$, or those consistent with a unique equilibrium. Results confirm that without adjustment costs (panel A), a positive response of consumption is no longer feasible. Output multipliers, on the other hand, can still exceed one should investment be sufficiently large. 
A. No Adjustment Costs $\left(\phi^{\prime \prime}=0\right)$

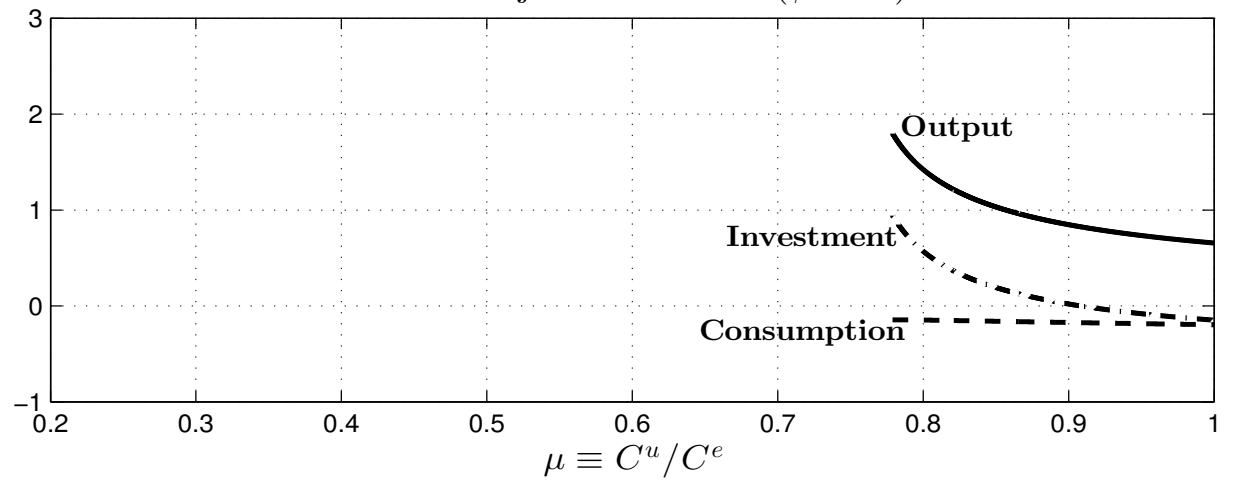

B. With Adjustment Costs $\left(\phi^{\prime \prime}<0\right)$

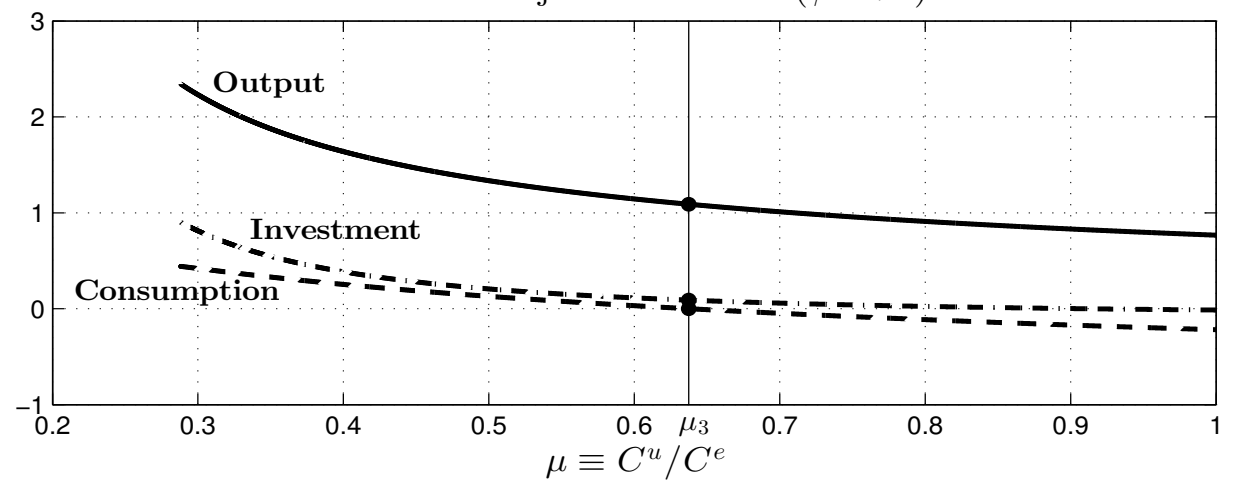

Fig. 6. Impact multipliers: capital accumulation

Notes: Impact multipliers for output, consumption, and investment as functions of the insurance coefficient $\mu$ are shown for the models without capital adjustment costs (A) and with adjustment costs included (B). Computations are based on the following calibration: $\beta=0.99, g=0.17, \rho=0.90, N=0.942, \alpha=1 / 3, \chi=2 / 3, \eta=6, \phi_{\pi}=1.50, \delta=0.025, \phi^{\prime \prime}(\delta)=\{0,-40\}$.

This condition is met whenever $\mu<0.86$, with investment increasing rapidly the closer $\mu$ gets to its threshold value. Over this interval, investment demand goes up for the usual reason. Growth in total employment increases the returns to capital, encouraging families to save more in the short run (e.g., Aiyagari et al., 1992).

So far, the restrictions imposed by equilibrium determinacy have precluded any assessment of the composition effects central to the results in section 2. One way to loosen these restrictions is to incorporate adjustment costs. Panel B of Figure 5 again shows regions of $(\mu, \chi)$ space associated with (in)determinacy, this time with $\phi^{\prime \prime}<0$. As is clear from the figure, adjustment costs greatly expand the range of insurance options consistent with a unique equilibrium. Now any value of $\mu$ above 0.3 is enough to ensure determinacy regardless of the degree of price stickiness. 
How these changes affect the link between unemployment insurance and the multipliers can be seen in Figure 6 (panel B). Overall the results are similar to the benchmark model. Output and consumption are less than one and zero under full insurance. And as unemployment benefits drop, both quantities along with the multiplier for investment get bigger. Like before, there exists a critical value, call it $\mu_{3}$, at which consumption is zero. Still output is greater than one at this point on account of investment. For insurance levels below $\mu_{3}$, which in the figure is about 0.64 , the composition effect becomes large enough to turn the consumption multiplier positive.

\section{Some Extensions and Quantitative Examples}

As a strictly empirical matter, the composition effect by itself is probably not strong enough to deliver the kinds of robust multiplier estimates sometimes found in macro-econometric studies of fiscal policy. For output to rise by an amount that exceeds the increase in government purchases, Figures 2, 4, and 6 suggest that consumption must drop by 30 percent or more for workers who become unemployed. A decline of this magnitude though seems large in comparison to published estimates from the micro literature reviewed earlier. Recall these studies typically report consumption losses in the neighborhood of 5 to 25 percent (Table 1). Yet even at the high end of this range, the simple models used thus far have little hope of matching the empirical evidence absent other transmission channels capable of boosting the economy's response to a spending increase.

In this section I extend the model to include other propagation mechanisms that have recently been used to study the effects of government spending. The aims are twofold. One is to determine whether large multipliers can be made consistent with an empirically plausible degree of unemployment insurance. I believe they can. And I demonstrate as much in an environment that combines three elements: preferences that value both private and government consumption, variable capital utilization, and an insurance arrangement that lies comfortably within the bounds of Table 1.

A second goal is to assess the credibility of the insurance mechanism by conducting a set of quantitative experiments that speak directly to some leading issues in the current policy debate. One issue concerns the effects of large and prolonged increases in government spending of the sort recently associated with the American Recovery and Reinvestment Act. Another deals with the idea that multipliers may be larger and more persistent than normal during periods in which monetary policy is expected to peg the interest rate for a known 
length of time, perhaps as a consequence of the zero lower bound. In both experiments I find that the extended model yields insights similar to those found in related work on the effectiveness of these types of fiscal programs. By contrast, imposing full insurance generates policy outcomes more at odds with mainstream views.

\section{A. Extensions}

To the model presented in section 3 I add endogenous capital utilization, government spending valued as a public good, and rule-of-thumb families along the lines of Galí et al. (2007). For reasons discussed later, my preferred specification will ultimately contain just the first two, but in the meantime I explore the implications of including the third. Below I outline how each of these extensions fits into the basic framework developed by Alexopoulos (2004). All concepts and definitions are the same as before unless noted otherwise.

Capital utilization. The family selects the rate $v_{t}$ at which capital is to be utilized in production. Leasing $K_{t}$ brings in $r_{t}^{k} v_{t} K_{t}$ units of rental income each period. But it also entails a cost in terms of the finished good equal to $\Psi\left(v_{t}\right) K_{t}$, where $\Psi\left(v_{t}\right)$ is increasing and convex. ${ }^{15}$ Updating the budget constraint to account for these resource flows gives

$$
C_{t}^{f}+I_{t}+\Psi\left(v_{t}\right) K_{t}+\frac{B_{t}}{P_{t}} \leq \frac{R_{t-1} B_{t-1}}{P_{t}}+r_{t}^{k} v_{t} K_{t}-T_{t}+\frac{1}{P_{t}} \int_{0}^{1} D_{t}(i) d i .
$$

Imposing market-clearing requirements on (16) produces the aggregate resource constraint

$$
Y_{t}=C_{t}+I_{t}+G_{t}+\Psi\left(v_{t}\right) K_{t}
$$

To see why utilization is helpful, consider how $v_{t}$ adjusts after a spending hike. Employment gains drive up the returns to capital, which the family captures in part by raising its utilization rate. For a given capital stock, increases in $v_{t}$ increase the marginal product of labor, to which firms respond by hiring even more workers. This demand-side momentum in the labor market strengthens the expansionary effects of policy operating through outward shifts in the no-shirking condition. The effect gets bigger the less costly it is to change $v_{t}{ }^{16}$

\footnotetext{
${ }^{15}$ I impose $v=1$ and $\Psi(1)=0$ and assume $\Psi^{\prime}(1) / \Psi^{\prime \prime}(1) \equiv \psi \geq 0$.

${ }^{16}$ The cost of adjusting $v_{t}$ is governed by $\psi \equiv \Psi^{\prime}(1) / \Psi^{\prime \prime}(1)$. It gets progressively larger as $\psi \rightarrow 0$, at which point the family sets $v_{t}=1$ every period as was implicitly assumed in the model of section 3 .
} 
Public goods. I incorporate public goods by reformulating utility as

$$
U\left(C_{t}^{j}+b G_{t}, e_{t}\right)=\ln \left(C_{t}^{j}+b G_{t}\right)+\theta \ln \left(H-\nu_{t}\left[h e_{t}+\xi\right]\right) .
$$

Preferences of member $j$ now depend on $C_{t}^{j}$ and $G_{t}$, and the sign of $b$ determines whether they are viewed as substitutes or complements. As explained by Fève, Matheron, and Sahuc (2013), $b<0$ implies that private and government consumption are Edgeworth complements in that higher values of the latter increase the marginal utility of the former, inducing families to consume more. Should the complementarity effect be sufficiently strong, the incentive to raise $C_{t}^{j}$ may offset the negative wealth effect of higher taxes. ${ }^{17}$

Swapping the original utility function for (17) also affects the supply side of the model in a logical way. As always, firms want to discourage shirking, which requires that job contracts satisfy an incentive compatibility constraint

$$
U\left(C_{t}^{e}+b G_{t}, e_{t}\right) \geq d U\left(C_{t}^{s}+b G_{t}, 0\right)+(1-d) U\left(C_{t}^{e}+b G_{t}, 0\right) .
$$

Cost minimization proceeds exactly as before. The only difference is that the ratio implied by the Solow condition (8) corresponds to $\tilde{C} \equiv\left(C_{t}^{e}+b G_{t}\right) /\left(C_{t}^{s}+b G_{t}\right)$. This generalizes the benchmark result to account for the effect of public goods on the wage contract.

Labor supply is once again characterized by a no-shirking condition. With government spending in the utility function, it takes the form

$$
h w_{t}=\frac{1}{1-s}\left(\frac{\tilde{C}-1}{\tilde{C}}\right)\left(C_{t}^{e}+b G_{t}\right) .
$$

Linking $C_{t}^{u}$ to $C_{t}^{e}$ is also different when $b \neq 0$. Equations (2), (4), and (19) imply

$$
\frac{C_{t}^{u}+b G_{t}}{C_{t}^{e}+b G_{t}}=1-\frac{1-\sigma}{1-s}\left(\frac{\tilde{C}-1}{\tilde{C}}\right) \equiv \mu(\sigma) .
$$

Notice that public goods alter the interpretation of $\mu$. No longer is it equivalent to $C_{t}^{u} / C_{t}^{e}$, which is the relevant measure of partial insurance in the model and the same concept used in research on the consumption effects of unemployment. Rather than being constant, this ratio now varies according to $\left(C_{t}^{u} / C_{t}^{e}\right)=\mu-(1-\mu) b\left(G_{t} / C_{t}^{e}\right)$.

\footnotetext{
${ }^{17}$ Studies that rely on Edgeworth complementarity as a transmission mechanism include Linnemann and Schabert (2004), Bouakez and Rebei (2007), Leeper, Traum, and Walker (2017), and Sims and Wolff (2018).
} 
Rule-of-thumb families. In the benchmark model all families participate in asset markets where they buy and sell bonds and accumulate capital. I consider an alternative setup here that assumes a fraction $\omega \in[0,1]$ never participate in these markets. They own no assets (or liabilities) and so consume only their after-tax labor income. In the spirit of Campbell and Mankiw (1989) and Galí et al. (2007), I refer to this population as "rule-of-thumb" families. The other $1-\omega$ have full access to capital markets and behave according to the same intertemporal optimization problem described earlier.

Preferences of a rule-of-thumb (ROT) family are the same as those of an optimizing one. And like the latter, the effort of its members is imperfectly observable. To simplify the analysis, I assume firms cannot tell which family type workers come from. The best they can do then, in terms of preventing shirking at the lowest cost, is to design a blanket contract, but one that makes the incentive compatibility constraint (18) hold with equality only for those who happen to be members of an optimizing family. The constraint for ROT workers, to be sure, will also hold (as a slackness condition) but will never bind in equilibrium. ${ }^{18}$ This arrangement, together with the assumption that firms allocate labor demand uniformly, implies that wages and employment probabilities will be the same for everyone.

Let $C_{r, t}^{e}$ and $C_{r, t}^{u}$ denote the consumption of employed and unemployed ROT workers. With no equity stake in firms, (2) and (4) require that these quantities satisfy

$$
\begin{aligned}
& C_{r, t}^{e}=-T_{t}+\left[1-\sigma\left(1-N_{t}\right)\right] h w_{t}, \\
& C_{r, t}^{u}=-T_{t}+\sigma N_{t} h w_{t} .
\end{aligned}
$$

From this point it is easy to rewrite $C_{r, t}^{e}$ and $C_{r, t}^{u}$ as functions of $\mu$. Just apply the definition from (20) along with the no-shirking condition (19) to obtain

$$
\begin{aligned}
& C_{r, t}^{e}=-T_{t}+N_{t} h w_{t}+\left(1-N_{t}\right)(1-\mu)\left(C_{o, t}^{e}+b G_{t}\right), \\
& C_{r, t}^{u}=C_{r, t}^{e}-(1-\mu)\left(C_{o, t}^{e}+b G_{t}\right) .
\end{aligned}
$$

Summing the activity of all workers produces the aggregate consumption identity

$$
C_{t}=N_{t}\left[(1-\omega) C_{o, t}^{e}+\omega C_{r, t}^{e}\right]+\left(1-N_{t}\right)\left[(1-\omega) C_{o, t}^{u}+\omega C_{r, t}^{u}\right],
$$

\footnotetext{
${ }^{18}$ I verify ex post that the equilibrium wage-effort pair satisfies the incentive compatibility constraint of ROT workers both in the steady state and along the transition path.
} 
where $C_{o, t}^{e}$ and $C_{o, t}^{u}$ are the consumption of workers who belong to an optimizing family.

In models with ROT agents, the method of government finance can have significant effects on fiscal multipliers. I follow Galí et al. (2007) in assuming that the government pursues a mix of lump-sum taxes and borrowing by implementing

$$
T_{t}=T+\phi_{g}\left(G_{t}-G\right)+\phi_{b}\left(\frac{B_{t-1}}{P_{t-1}}-\frac{B}{P}\right) \text {. }
$$

For suitable values of $\phi_{g}$ and $\phi_{b}$, (21) permits substantial deficit financing in the short run while preserving stable debt dynamics in the long run. A lower tax burden, even if only temporary, boosts the consumption response of ROT workers since this group is more sensitive to disposable income. Such "non-Ricardian" behavior helps cushion aggregate demand from the wealth consequences of higher government spending. This effect gets bigger the greater the fraction $\omega$ of ROT families.

\section{B. Government Spending Multipliers}

There are two issues that need to be addressed before commenting on the results. Until now, I have framed the discussion in terms of impact multipliers. While analytically convenient, this measure obviously ignores the cumulative effects of a spending shock over longer horizons. In this section I follow Mountford and Uhlig (2009) by reporting present-value multipliers, an alternative concept that accounts for the entire response path up to a given period and correctly discounts future macroeconomic outcomes.

Take Gross Domestic Product, for example, defined in the model as $Z_{t} \equiv C_{t}+I_{t}+G_{t}$. Its present-value multiplier is

$$
\text { present-value multiplier }(l) \equiv \frac{E_{t} \sum_{j=0}^{l}(1 / R)^{j} \triangle Z_{t+j}}{E_{t} \sum_{j=0}^{l}(1 / R)^{j} \triangle G_{t+j}},
$$

which gives the discounted value (total effect) of changes in GDP over the next $l$ periods caused by a unit shock to the present value of government spending in period $t .^{19}$ For $l=0$, the present-value multiplier is the same as the impact multiplier $d Z_{t} / d G_{t}$.

The second issue concerns the choice of values for the insurance coefficient $\mu$ and auxiliary parameters $\left(\psi, b, \omega, \phi_{g}, \phi_{b}\right)$. Regarding capital utilization, I fix $\psi=0.5$. Published estimates tend to fall between 0.1 and 0.9 . My calibration is at the midpoint where utilization costs are

\footnotetext{
${ }^{19}$ Multipliers for private consumption, investment, and the real wage are defined analogously.
} 
fairly conservative. ${ }^{20}$ As for public goods, I set $b=-0.2$. This value is close to the estimate in Leeper et al. (2017) and implies some degree of complementarity between private and government consumption. Informed by results in Coenen and Straub (2005), Bilbiie, Meier, and Müller (2008), and Forni, Monteforte, and Sessa (2009), I fix the share of ROT families $\omega$ at 0.25 . A small value of $\omega$ limits any impact non-Ricardian forces can exert on the multiplier process, which helps keep the onus on partial insurance to do most of the heavy lifting in the model. Turning to the fiscal rule (21), I follow Galí et al. (2007) by setting $\phi_{g}=0.1$ and $\phi_{b}=0.33$. As shown by the authors, these values are consistent with VAR-based estimates of deficit and spending dynamics.

For information on $\mu$, I look to evidence from the microeconomic studies compiled in Table 1. Many examples there use survey data to evaluate the average drop in food consumption that occurs when a person becomes unemployed. Across this group, estimates range from 6 to 19 percent. Yet I suspect some of these findings may understate the actual consumption loss experienced by displaced workers. For starters, most of the samples deliberately exclude observations that show large changes in consumption spending. Although this helps insulate results from problems of misreporting, it probably biases upward estimates of $C^{u} / C^{e}$. Second, some studies report annual declines without conditioning on the length of time spent out of work. Chodorow-Reich and Karabarbounis (2016) bring up this point and argue that affected estimates should be increased by a factor of three since the typical unemployment spell lasts only 17 weeks. Finally, restricting the analysis to food consumption ignores spending categories that are more sensitive to job loss. The classic study by Burgess et al. (1981) indeed finds that where obligated or necessary expenditures fall by 12.7 percent from four weeks prior to eight weeks after the onset of unemployment, all other consumption categories fall by a combined 28 percent.

In what follows, I fix the value of $\mu$ such that the model delivers $C^{u} / C^{e}=0.82$. The implied consumption drop of 18 percent is near the average of the subset of estimates in Table 1 that utilize a measure of total consumption. While this number undoubtedly masks a great deal of heterogeneity across individuals, I view it as a useful approximation of the extent to which the typical U.S. worker is insured against unemployment risk.

Figure 7 graphs present-value multipliers for GDP, consumption, and investment out to a ten-year horizon. The first row corresponds to a baseline that features only partial insurance and variable utilization (solid lines). To this model I add public goods (dashed lines), ROT

\footnotetext{
${ }^{20}$ Levin, Onatski, Williams, and Williams (2006), Justiniano, Primiceri, and Tambalotti (2010), and Altig, Christiano, Eichenbaum, and Lindé (2011) report values between 0.1 to 0.2. Smets and Wouters (2007) and Galí, Smets, and Wouters (2012) obtain estimates closer to 0.8 .
} 

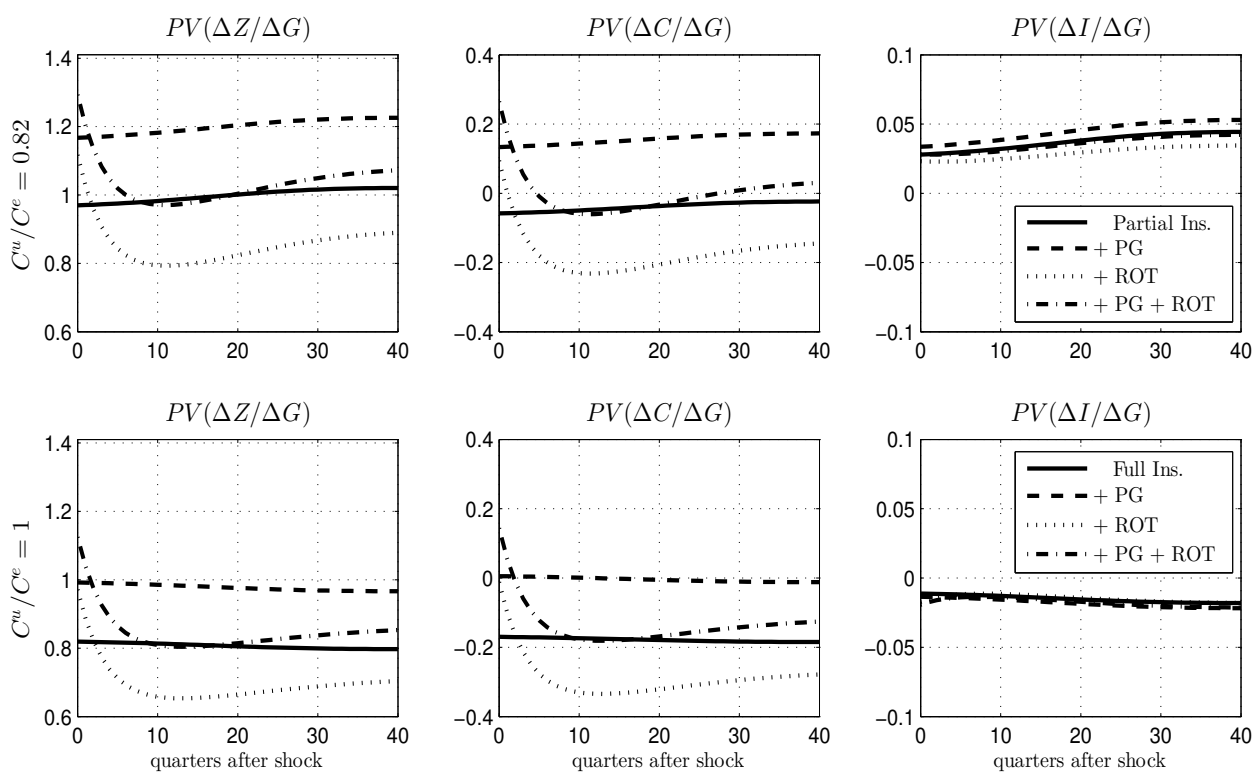

Fig. 7. Present-value multipliers: extended model

Notes: Present-value multipliers for GDP, consumption, and investment are shown for versions of the extended model with partial (row one) and full insurance (row two). Added to each baseline (solid lines) are public goods (dashed lines), ROT families (dotted lines), and public goods and ROT families together (dash-dotted lines). Computations are based on the following calibration: $\beta=0.99, g=0.17, \rho=0.90, N=0.942, \alpha=1 / 3, \chi=2 / 3, \eta=6, \phi_{\pi}=1.50, \delta=0.025, \phi^{\prime \prime}(\delta)=-40$, $\psi=0.5, b=\{0,-0.2\}, \omega=\{0,0.25\}, \phi_{g}=0.1, \phi_{b}=0.33, \mu=\{0.80988,1\}$.

families (dotted lines), and then both public goods and ROT families together (dash-dotted lines). Row two alters the baseline to full insurance $\left(C^{u} / C^{e}=1\right)$ with variable utilization.

Take the partial insurance model first. At no point is the present-value multiplier for consumption greater than zero. Still GDP rises above one after five years due to the positive response of investment. Adding public goods to the mix amplifies the effects of government spending. The multipliers in this case are on par with those found at the upper end of the empirical range, about 0.16 for consumption and 1.2 for GDP. Investment multipliers are also at their highest in this model, settling above 0.05 in the long run. Swapping out public goods for ROT families actually weakens the economy's response to a spending shock. The impact effects are about the same as before, but the cumulative effects decrease rapidly as taxes adjust to bring down the deficit. Inserting public goods back into the model shifts up the multipliers but does nothing to reverse the drop in persistence. Both consumption and GDP remain short-lived, falling below zero and one, respectively, after six quarters. ${ }^{21}$

\footnotetext{
${ }^{21}$ In a model with ROT agents but Calvo-type sticky wages, Leeper et al. (2017) find that most of the increases in output and consumption go away after two years.
} 
For this reason, my preferred version of the extended model sets the mass of ROT families $\omega=0$. It is also the version that will be used to run the policy experiments described in the next two sections.

The second row illustrates how important partial insurance is for the transmission of government spending shocks. With full insurance, present-value multipliers become significantly lower (compared to row one) across all permutations of the model. Even in the public goods case, the declines are enough to push consumption to zero and GDP below one at any horizon. In principle, bigger multipliers could be attained with a much smaller (more negative) value of $b$, that is, through stronger consumption complementarities. But to me, such over-reliance on this mechanism is empirically less palatable. ${ }^{22}$

\section{The American Recovery and Reinvestment Act of 2009}

A simple AR(1) process for government purchases, while useful for studying the properties of a model, is not a realistic way of describing the types of large-scale spending initiatives recently implemented in the U.S. and other advanced countries. One example is the $\$ 787$ billion American Recovery and Reinvestment Act (ARRA) that was signed into law in early 2009. As documented in Cogan, Cwik, Taylor, and Wieland (2010), most of the payments authorized by this legislation were to be phased in gradually over five years. In this section I analyze the effects of the ARRA by simulating the time profile of government spending in the extended model. To see how much influence the insurance arrangement has on equilibrium outcomes, I run the simulation once with $C^{u} / C^{e}=0.82$ and a second time with $C^{u} / C^{e}=1$.

The policy experiments carried out below are similar to ones in Uhlig (2010) and Zubairy (2014). In particular, the program of government spending under the ARRA, as identified by Cogan et al. (2010), is fed into the model as a sequence of anticipated shocks. So after observing the initial shock in the first quarter of 2009, households and firms have perfect foresight about future spending and incorporate that information into their expectations.

Figure 8 shows the path of government purchases through 2014 and the response to these shocks under partial (solid lines) and full insurance (dashed lines). The effects on GDP start off small but rise quickly in the first two years of operation. What's more, the additional output at this stage is larger in the partial insurance case by as much as 0.16 percentage points (from a common steady state). After 2010, the stimulus effects begin to fade and continue until the spending increases expire in 2014.

\footnotetext{
${ }^{22}$ The long-run output multiplier of 1.3 obtained by Fève et al. (2013) requires an estimate of $b=-0.95$, indicating a high degree of complementarity between private and government consumption.
} 

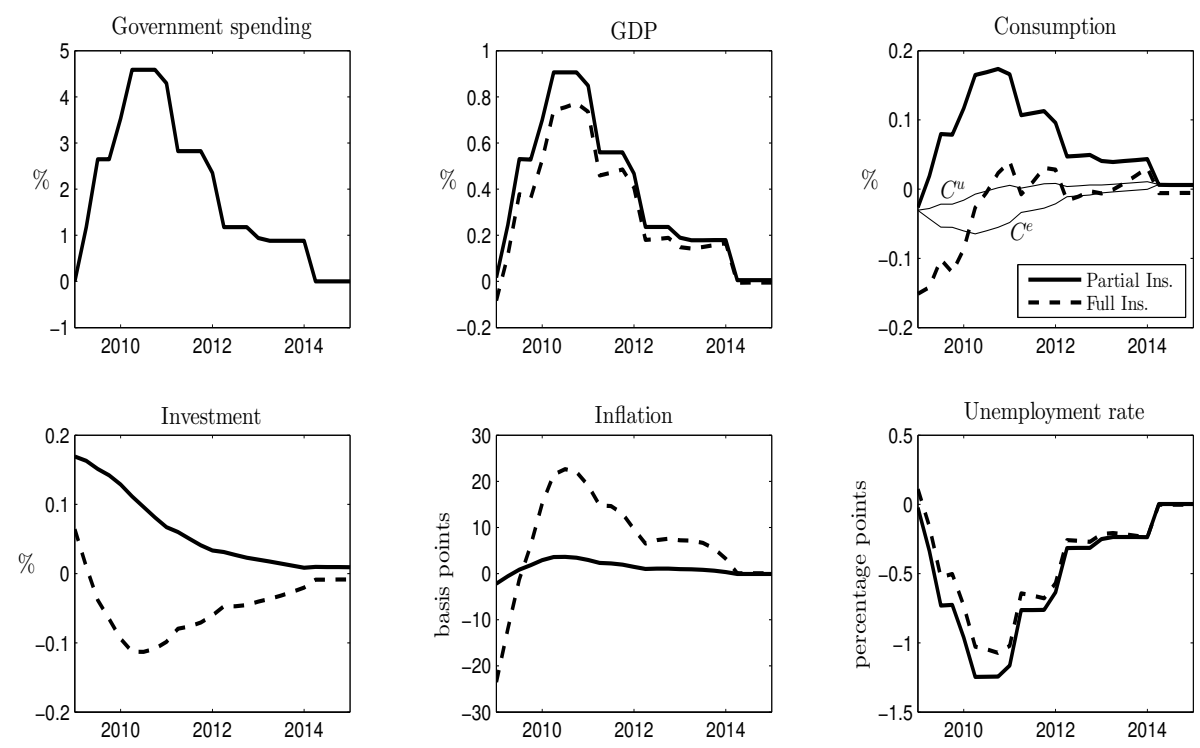

Fig. 8. ARRA simulations: response paths

Notes: The economy's response to the path of government spending implied by the ARRA is shown for the partial (solid lines) and full insurance (dashed lines) versions of the extended model. All variables are in percent deviations from steady state except for inflation and the unemployment rate, which have been converted to annualized basis points and absolute percentage points, respectively. Simulations are based on the following calibration: $\beta=0.99, g=0.17, N=0.942, \alpha=1 / 3, \chi=2 / 3$, $\eta=6, \phi_{\pi}=1.50, \delta=0.025, \phi^{\prime \prime}(\delta)=-40, \psi=0.5, b=-0.2, \omega=0, C^{u} / C^{e}=\{0.82,1\}$.

Differences in the size of the expansion once again trace to aggregate consumption. With full insurance, consumption falls immediately by 0.15 percent as families anticipate the inevitable run up in taxes. Under partial insurance, there is only a slight drop in the initial quarter, followed by two straight years of positive growth. This increase, to be sure, occurs at the same time individual consumption is being crowded out by the ARRA. Notice that both $C_{t}^{e}$ and $C_{t}^{u}$ (thin solid lines) respond negatively after 2009, although the change in $C_{t}^{e}$ is greater and more persistent. ${ }^{23}$ It follows that the rise in $C_{t}$ must be due to positive composition effects operating along the extensive margin. These effects are clearly visible in the unemployment rate, which is a full 1.25 percentage points below its long-run average at the height of the stimulus episode in late 2010.

To shed light on the cumulative effects of the ARRA, Figure 9 converts the response functions into present-value multipliers. Under full insurance (dashed lines), consumption and GDP are well below zero and one for all of 2009 and most of 2010. But under partial

\footnotetext{
${ }^{23}$ The implication is that spending shocks may temporarily reduce the consumption inequality associated with job loss. Related findings on the distributional effects of government spending can be found in Galí et al. (2007), Anderson, Inoue, and Rossi (2016), and Ma (2019).
} 

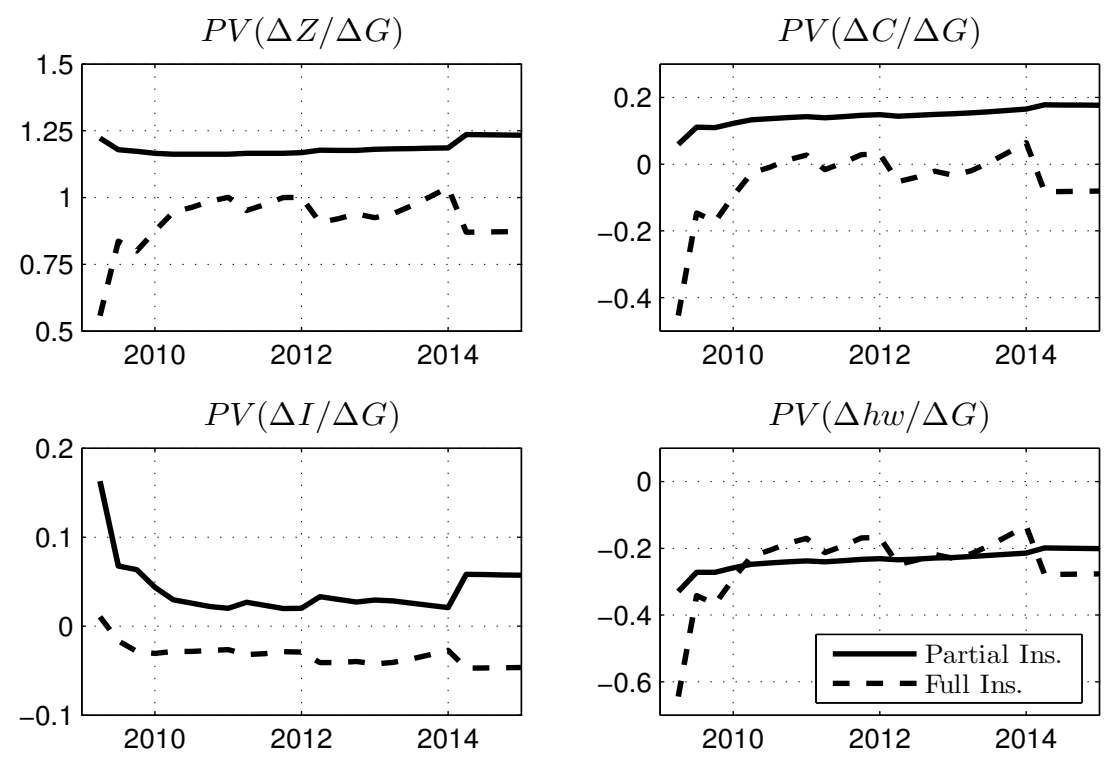

Fig. 9. ARRA simulations: present-value multipliers

Notes: Present-value multipliers for GDP, consumption, investment, and the real wage implied by the path of the economy under the ARRA are shown for the partial (solid lines) and full insurance (dashed lines) versions of the extended model. Simulations are based on the following calibration: $\beta=0.99, g=0.17, N=0.942, \alpha=1 / 3, \chi=2 / 3, \eta=6, \phi_{\pi}=1.50$, $\delta=0.025, \phi^{\prime \prime}(\delta)=-40, \psi=0.5, b=-0.2, \omega=0, C^{u} / C^{e}=\{0.82,1\}$.

insurance (solid lines), consumption and GDP are significantly above these benchmarks the whole time. The maximum effects are 0.18 and 1.24 and arrive as late as the second quarter of 2014. ${ }^{24}$ The two cases also have different implications for investment. With partial insurance, the multiplier jumps to 0.16 right after the policy announcement but diminishes rapidly from then on. The full insurance model shows investment being crowded out in all but the initial period (see also Figure 8).

I conclude this section with some comments on the real wage and inflation. Like the example depicted in Figure 3, wages decline in the extended model regardless of the terms of insurance, resulting in negative multipliers from start to finish. For the first year though, the size of the wage cut is noticeably larger under full insurance. A quick look back at the no-shirking condition (19) reveals why. The crowding out of individual consumption puts downward pressure on the real wage. But as is clear from Figure 8, the drop is smaller, albeit it more persistent, under partial insurance. This behavior both dampens and prolongs the countercyclical adjustment of the real wage compared to the full insurance case.

\footnotetext{
${ }^{24}$ In their preliminary analysis of the macroeconomic impact of the ARRA legislation, Romer and Bernstein (2009) report medium-run forecasts of the GDP multiplier in the neighborhood of 1.5.
} 
Of course less variation in the wage means less variation in marginal cost, and in turn, a more stable response path of inflation. Evidence of this effect can be seen in Figure 8. Under full insurance, annualized inflation promptly falls by 25 basis points and then rises by about 50 basis points over the next six quarters. The changes observed under partial insurance are trivial by comparison. ${ }^{25}$

\section{A Nominal Interest Rate Peg}

Much of the latest research on fiscal policy has been motivated by the experience of nearzero interest rates that took place from 2009 to 2015. Since then, many have argued that multipliers may be larger than normal should monetary policy accommodate government spending by keeping interest rates fixed for some time (e.g., Eggertsson, 2011; Woodford, 2011; Christiano, Eichenbaum, and Rebelo, 2011). In this section I examine the consequences of such accommodative or "passive" monetary policy. Highlighting the role of unemployment insurance in affecting outcomes is still the main focus. So I again simulate the model for the two cases where $C^{u} / C^{e}=\{0.82,1\}$.

The joint policy experiment I have in mind is similar to one in Leeper et al. (2017). The fiscal side dictates that government spending rise by 1 percent for two years before settling into its original autoregressive track, or

$$
G_{t}= \begin{cases}1.01 G & \text { for } t=1,2, \ldots, 8 \\ (1-\rho) G+\rho G_{t-1} & \text { for } t>8\end{cases}
$$

Meanwhile, the central bank sets

$$
\ln R_{t}= \begin{cases}\ln R & \text { for } t=1,2, \ldots, J \\ \ln R+\phi_{\pi} \ln \pi_{t} & \text { for } t>J\end{cases}
$$

This procedure calls for pegging the nominal interest rate at a fixed value (the steady state) for $J$ quarters but reverting to the benchmark rule (14) thereafter.

I implement the peg using methods developed by Laseen and Svensson (2011). The basic idea is to augment (14) with a series of "shadow shocks" designed so that the peg holds for

\footnotetext{
${ }^{25}$ The absence of any significant inflationary effects of the ARRA echoes results in Dupor and Li (2015).
} 

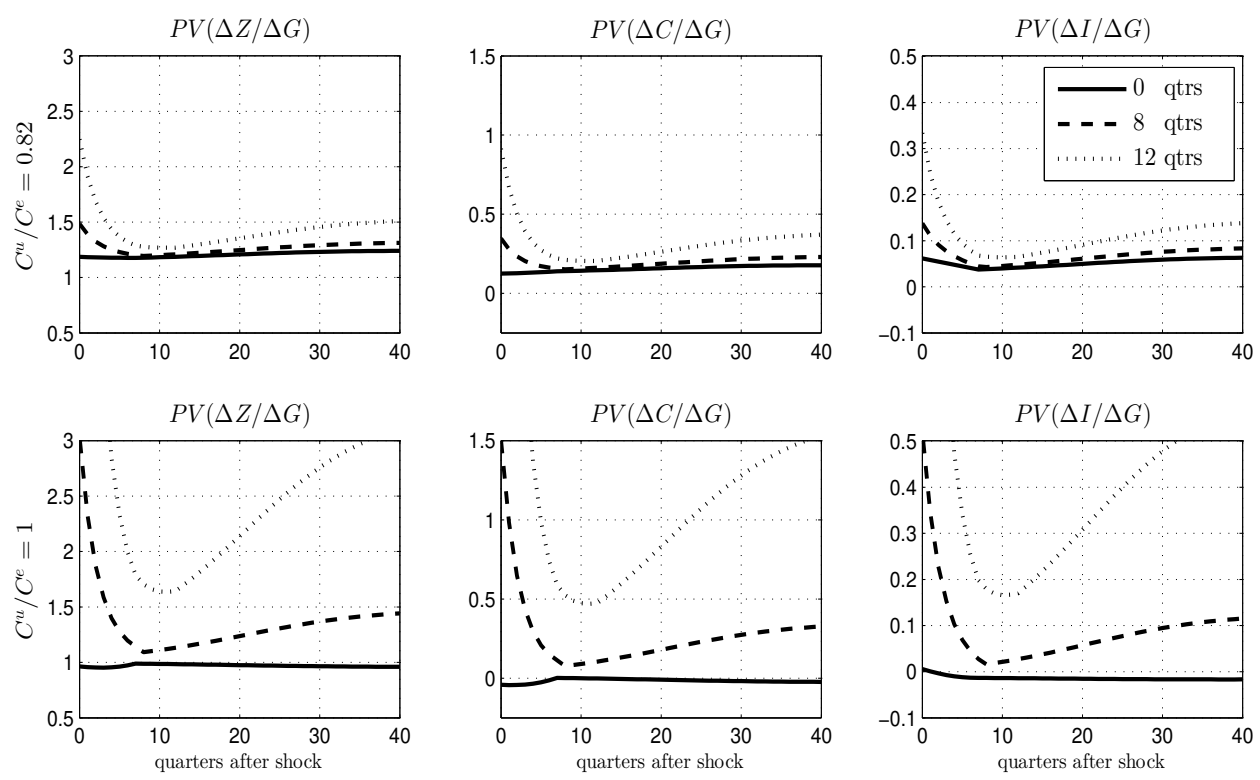

Fig. 10. Interest rate peg: present-value multipliers

Notes: Present-value multipliers for GDP, consumption, and investment are shown for versions of the extended model with a nominal interest rate peg of zero (solid lines), eight (dashed lines), and twelve-quarter (dotted lines) durations. Simulations are based on the following calibration: $\beta=0.99, g=0.17, \rho=0.90, N=0.942, \alpha=1 / 3, \chi=2 / 3, \eta=6, \phi_{\pi}=1.50, \delta=0.025$, $\phi^{\prime \prime}(\delta)=-40, \psi=0.5, b=-0.2, \omega=0, C^{u} / C^{e}=\{0.82,1\}$.

the desired number of periods. In this way, current policy can be written as

$$
\ln R_{t}=\ln R+\phi_{\pi} \ln \pi_{t}+\sum_{j=0}^{J-1} \alpha_{j} \epsilon_{t+j, t}
$$

where $\left\{\epsilon_{t+j, t}\right\}_{j=0}^{J-1}$ are shocks (of unit size) observed at time $t$ that do not affect the interest rate until $t+j$. Auxiliary coefficients $\left\{\alpha_{j}\right\}$ are then chosen to make the shadow shocks cancel out any movements in $R_{t}$ during the first $J$ periods. Because the shocks are seen ahead of time, agents know the exact duration of the peg and adjust their expectations accordingly.

Figure 10 graphs present-value multipliers implied by the policy simulation described above. The first row is for the partial insurance model and considers cases in which $J$ equals zero (solid lines), eight (dashed lines), and twelve quarters (dotted lines). The second row evaluates the same three peg lengths in the full insurance model.

Results from the partial insurance model appear broadly consistent with the recent literature. To start, multipliers for GDP, consumption, and investment are all higher when the interest rate is pegged, and the effects increase the longer the peg lasts (e.g., Woodford, 

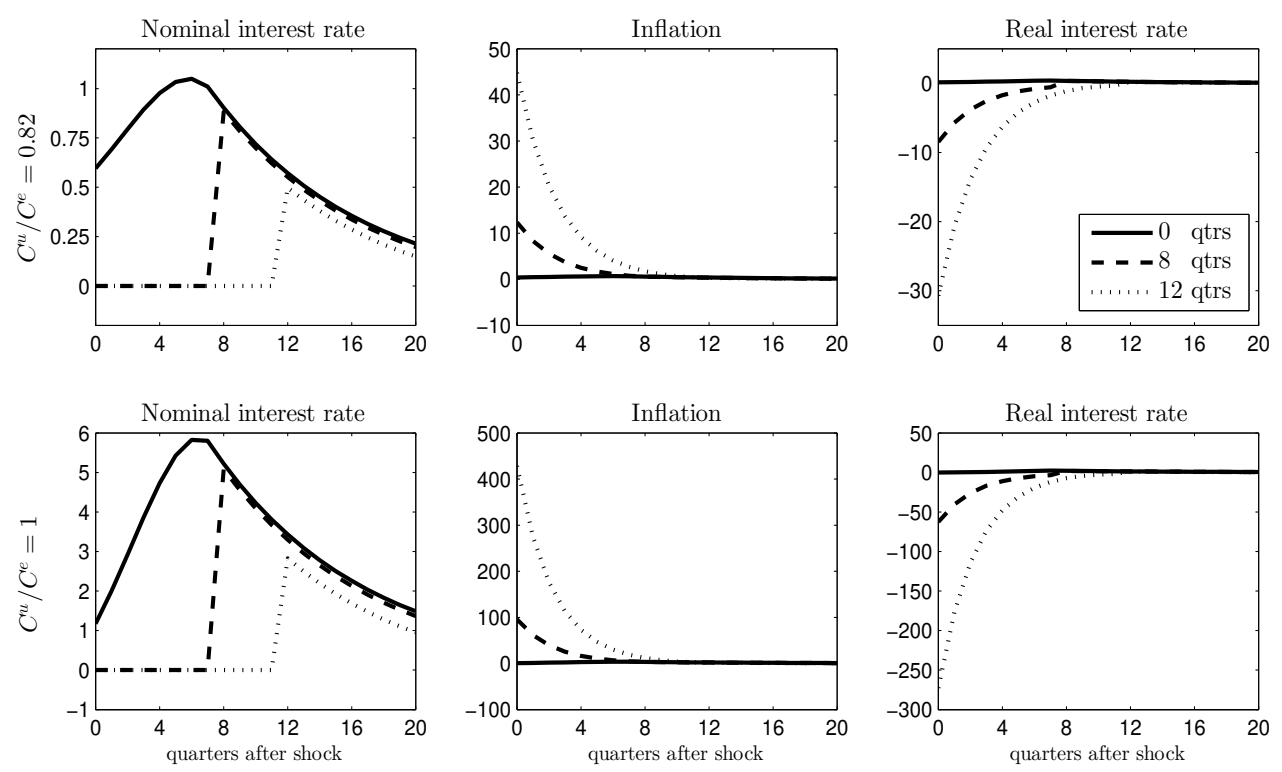

Fig. 11. Interest rate peg: response paths

Notes: The response of interest rates and inflation to the path of government spending are shown for versions of the extended model with a nominal interest rate peg of zero (solid lines), eight (dashed lines), and twelve-quarter (dotted lines) durations. All variables are in annualized basis points. Simulations are based on the following calibration: $\beta=0.99, g=0.17, \rho=0.90$, $N=0.942, \alpha=1 / 3, \chi=2 / 3, \eta=6, \phi_{\pi}=1.50, \delta=0.025, \phi^{\prime \prime}(\delta)=-40, \psi=0.5, b=-0.2, \omega=0, C^{u} / C^{e}=\{0.82,1\}$.

2011; Erceg and Lindé, 2014). A two-year peg, for example, produces an impact multiplier for GDP equal to 1.5. A three-year peg raises it to about 2.2. These quantities are close to values reported by Christiano et al. (2011) who run a similar experiment but in the context of an estimated medium-size DSGE model of the postwar U.S. economy.

Another familiar result is that present-value multipliers are always highest in the impact period. Leeper et al. (2017) attribute this to the well-known expected inflation channel articulated by Christiano et al. (2011) and others. In short, a fixed nominal rate causes a decrease in the real interest rate since the fiscal expansion is associated with higher expected inflation. A lower real rate encourages private spending, leading to a further rise in expected inflation and so on. The full equilibrium effect can be seen in Figure 11 (row one), which graphs the simulated response of interest rates and inflation in each case. Notice that the amount by which the real interest rate falls increases with the duration of the peg. Moreover, conditional on a given peg, the biggest declines occur upon impact, that is, when the economy is furthest from the liftoff period for the nominal interest rate.

Now contrast these results with the full insurance model (row two), where the effects are literally an order of magnitude larger. Under a three-year peg, for example, inflation surges 
more than 400 basis points (annualized), causing the real rate to plummet by some 275 basis points. Such a large drop in the real rate obviously cannot happen without a significant rise in production, evidence of which is clear from Figure 10. Following the initial increase in government spending, multipliers for GDP, consumption, and investment are huge and, to my knowledge, far beyond any credible estimates of the effects of similar programs. ${ }^{26}$

What explains the relative stability of the partial insurance model in this experiment? It turns out that full insurance has consequences under an interest rate peg akin to increases in the degree of price flexibility. Both amplify the expected inflation effect on the real interest rate. As shown by Christiano et al. (2011), Kiley (2016), and Leeper et al. (2017), spending multipliers go up-often dramatically-as price changes become more frequent. This happens because greater price flexibility leads to a larger response of inflation (assuming passive monetary policy) and hence a larger adjustment of the real interest rate. ${ }^{27}$

Moving from partial to full insurance, it seems, has similar effects on inflation. These similarities emerge because partial insurance, through its influence on the wage-setting process, actually bolsters the amount of endogenous price rigidity in the model. So even though the frequency of price changes is the same, the magnitude of those changes are smaller under partial insurance (e.g., Givens 2008; Givens, 2011). And like increases in the exogenous length of price fixity, this works to moderate the impact of spending shocks on inflation (see also Figure 8). The net result is a smaller reduction in the real interest rate and thus a smaller, but more plausible, upturn in private spending.

\section{Concluding Remarks}

The basic argument laid out in these pages goes something like this. The negative (individual) wealth effects of government spending predominant in most business cycle models are not necessarily inconsistent with the aggregate time-series evidence. Once one accounts for the composition of private spending between workers and nonworkers, it is possible for aggregate consumption to go up after a tax-financed rise in government purchases. But for this to happen, two conditions must be met. The spending increase must result in more workers and fewer nonworkers, and consumption levels must be higher for workers.

I flesh out these ideas in the shirking, efficiency-wage model of Alexopoulos (2004) with

\footnotetext{
${ }^{26}$ Impact multipliers in this case are 10,6.7, and 2.3. None are actually visible in the figure though because the range of values have been truncated to facilitate comparisons between partial and full insurance.

${ }^{27}$ This property is closely related to the more general volatility paradox of sticky price models recently discussed in Werning (2011) and Bhattarai, Eggertsson, and Schoenle (2018).
} 
partial unemployment insurance. The main theoretical result demonstrates that multipliers for consumption and output may exceed zero and one if the amount of insurance held by individuals is sufficiently small. This threshold, however, lies somewhat outside the normal range of estimates from the micro literature on the consumption effects of unemployment. To strengthen the underlying transmission channel, I add to the baseline model capital utilization and public goods. Not only does this extended version produce sizable multipliers at insurance levels within the normal range, it also yields credible predictions regarding the effectiveness of contemporary stimulus programs like the ARRA and the Federal Reserve's accommodation of fiscal policy through a transient interest rate peg.

This research makes some assumptions designed to spotlight-as openly as possible-the link between unemployment insurance and government spending multipliers. As a result, it leaves out details the broader policy literature suggests may be relevant. One is the financing of public consumption by means of distortionary taxes. Recent studies show that multipliers may be lower if the only source of revenue is a marginal income tax (e.g., Drautzburg and Uhlig, 2015). Another issue concerns the absence of any mechanism that would induce stickiness in the nominal wage. To date, there is ample evidence showing that nominal wage changes are infrequent (e.g., Barattieri, Basu, and Gottschalk, 2014). Accounting for this type of rigidity may have nontrivial effects on the response of income and consumption to a fiscal shock (e.g., Colciago, 2011; Furlanetto, 2011; Dupor, Li, and Li, 2018).

Perhaps the most controversial assumption is the representative family structure, a useful modeling device that separates intertemporal decisions from the consumption choices of individuals. Relaxing this assumption would allow workers who face uninsurable idiosyncratic job risk to smooth consumption by means of precautionary saving. Ravn and Sterk (2017) explore this idea using a Diamond-Mortensen-Pissarides search model with government unemployment benefits. While it contains no formal discussion of fiscal policy, their analysis does show how financial market incompleteness and sticky prices together amplify the cyclical effects of labor market shocks. Hagedorn, Manovskii, and Mittman (2019) explicitly measure the size of government spending multipliers in the context of a New Keynesian model with incomplete markets. But their framework omits the sort of frictions needed to generate positive unemployment. Combining aspects of both studies may well provide new insights on the fiscal consequences of unemployment insurance policies. 


\section{References}

Abel, Andrew B. and Blanchard, Olivier J. "An Intertemporal Model of Saving and Investment." Econometrica, May 1983, 51(3), pp. 675-92.

Aguiar, Mark and Hurst, Erik. "Consumption versus Expenditure." Journal of Political Economy, October 2005, 113(5), pp. 919-48.

Aiyagari, S. Rao; Christiano, Lawrence J. and Eichenbaum, Martin. "The output, employment, and interest rate effects of government consumption." Journal of Monetary Economics, October 1992, 30(1), pp. 73-86.

Alexopoulos, Michelle. "Unemployment and the business cycle." Journal of Monetary Economics, March 2004, 51(2), pp. 277-98.

- "Shirking in a monetary business cycle model." Canadian Journal of Economics, August 2006, 39(3), pp. 689-718.

- "A monetary business cycle model with unemployment." Journal of Economic Dynamics and Control, December 2007, 31(12), pp. 3904-40.

Altig, David; Christiano, Lawrence J.; Eichenbaum, Martin and Lindé, Jesper. "Firm-specific capital, nominal rigidities and the business cycle." Review of Economic Dynamics, April 2011, 14(2), pp. 225-47.

Anderson, Emily; Inoue, Atsushi and Rossi, Barbara. "Heterogeneous Consumers and Fiscal Policy Shocks." Journal of Money, Credit and Banking, December 2016, 48(8), pp. 1877-88.

Barattieri, Alessandro; Basu, Susanto and Gottschalk, Peter. "Some Evidence on the Importance of Sticky Wages." American Economic Journal: Macroeconomics, January 2014, 6(1), pp. 70-101.

Barro, Robert J. and Redlick, Charles J. "Macroeconomic Effects From Government Purchases and Taxes." The Quarterly Journal of Economics, February 2011, 126(1), pp. 51-102.

Baxter, Marianne and King, Robert G. "Fiscal Policy in General Equilibrium." The American Economic Review, June 1993, 83(3), pp. 315-34.

Ben Zeev, Nadav and Pappa, Evi. "Chronicle of a War Foretold: The Macroeconomic Effects of Anticipated Defence Spending Shocks." The Economic Journal, August 2017, 127(603), pp. 1568-97.

Bhattarai, Saroj; Eggertsson, Gauti B. and Schoenle, Raphael. "Is increased price flexibility stabilizing? Redux." Journal of Monetary Economics, December 2018, 100, pp. 66-82. 
Bilbiie, Florin O. "Nonseparable Preferences, Fiscal Policy Puzzles, and Inferior Goods." Journal of Money, Credit and Banking, March-April 2009, 41(2-3), pp. 443-50.

- "Nonseparable Preferences, Frisch Labor Supply, and the Consumption Multiplier of Government Spending: One Solution to a Fiscal Policy Puzzle." Journal of Money, Credit and Banking, February 2011, 43(1), pp. 221-51.

Bilbiie, Florin O.; Meier, André and Müller, Gernot J. "What Accounts for the Changes in U.S. Fiscal Policy Transmission?" Journal of Money, Credit and Banking, October 2008, 40(7).

Blanchard, Olivier and Perotti, Roberto. "An Empirical Characterization of the Dynamic Effects of Changes in Government Spending and Taxes on Output." The Quarterly Journal of Economics, November 2002, 117(4), pp. 1329-68.

Bouakez, Hafedh and Rebei, Nooman. "Why does private consumption rise after a government spending shock?" Canadian Journal of Economics, August 2007, 40(3), pp. $954-79$.

Browning, Martin and Crossley, Thomas F. "Unemployment insurance benefit levels and consumption changes." Journal of Public Economics, April 2001, 80(1), pp. 1-23.

Brückner, Markus and Pappa, Evi. "Fiscal Expansions, Unemployment, and Labor Force Participation: Theory and Evidence." International Economic Review, November 2012, 53(4), pp. 1205-28.

Burgess, Paul L.; Kingston, Jerry L.; St. Louis, Robert D. and Sloane, Joseph T. "Changes in Spending Patterns Following Unemployment." U.S. Department of Labor Employment and Training Administration Occasional Paper 81-3, Washington, DC, 1981.

Burnside, Craig; Eichenbaum, Martin and Fisher, Jonas D.M. "Fiscal shocks and their consequences." Journal of Economic Theory, March 2004, 115(1), pp. 89-117.

Calvo, Guillermo A. "Staggered prices in a utility-maximizing framework." Journal of Monetary Economics, September 1983, 12(3), pp. 383-98.

Campbell, John Y. and Mankiw, N. Gregory. "Consumption, Income and Interest Rates: Reinterpreting the Time Series Evidence." in Olivier J. Blanchard and Stanley Fischer, eds., NBER Macroeconomics Annual 1989, 4, MIT Press, November 1989, pp. 185-216.

Chetty, Raj and Szeidl, Adam. "Consumption Commitments and Risk Preferences." The Quarterly Journal of Economics, May 2007, 122(2), pp. 831-77. 
Chodorow-Reich, Gabriel and Karabarbounis, Loukas. "The Cyclicality of the Opportunity Cost of Employment." Journal of Political Economy, December 2016, 124(6), pp. 1563-618.

Christiano, Lawrence J.; Eichenbaum, Martin and Rebelo, Sergio. "When Is the Government Spending Multiplier Large?" Journal of Political Economy, February 2011, 119(1), pp. 78-121.

Coenen, Günter and Straub, Roland. "Does Government Spending Crowd in Private Consumption? Theory and Empirical Evidence for the Euro Area." International Finance, December 2005, 8(3), pp. 435-70.

Cogan, John F.; Cwik, Tobias; Taylor, John B. and Wieland, Volker. "New Keynesian versus old Keynesian government spending multipliers." Journal of Economic Dynamics and Control, March 2010, 34(3), pp. 281-95.

Colciago, Andrea. "Rule-of-Thumb Consumers Meet Sticky Wages." Journal of Money, Credit and Banking, March-April 2011, 43(2-3), pp. 325-53.

Drautzburg, Thorsten and Uhlig, Harald. "Fiscal stimulus and distortionary taxation." Review of Economic Dynamics, October 2015, 18(4), pp. 894-920.

Dupor, Bill and Li, Rong. "The expected inflation channel of government spending in the postwar U.S." European Economic Review, February 2015, 74, pp. 36-56.

Dupor, Bill; Li, Rong and Li, Jingchao. "Sticky Wages, Monetary Policy and Fiscal Policy Multipliers." Federal Reserve Bank of St. Louis Working Paper 2017-007B, April 2018.

Dynarski, Susan; Gruber, Jonathan; Moffitt, Robert A. and Burtless, Gary. "Can Families Smooth Variable Earnings?" Brookings Papers on Economic Activity, 1997, No. 1, pp. 229-303.

East, Chloe N. and Kuka, Elira. "Reexamining the consumption smoothing benefits of Unemployment Insurance." Journal of Public Economics, December 2015, 132, pp. 32-50.

Eggertsson, Gauti B. "What Fiscal Policy is Effective at Zero Interest Rates?" in Daron Acemoglu and Michael Woodford, eds., NBER Macroeconomics Annual 2010, 25, University of Chicago Press, May 2011, pp. 59-112.

Erceg, Christopher and Lindé, Jesper. "Is There a Fiscal Free Lunch in a Liquidity Trap?" Journal of the European Economic Association, February 2014, 12(1), pp. 73-107.

Fève, Patrick; Matheron, Julien and Sahuc, Jean-Guillaume. "A Pitfall with Estimated DSGE-Based Government Spending Multipliers." American Economic Journal: Macroeconomics, October 2013, 5(4), pp. 141-78. 
Fisher, Jonas D.M. and Peters, Ryan. "Using Stock Returns to Identify Government Spending Shocks." The Economic Journal, May 2010, 120(544), pp. 414-36.

Forni, Lorenzo; Monteforte, Libero and Sessa, Luca. "The general equilibrium effects of fiscal policy: Estimates for the Euro area." Journal of Public Economics, April 2009, 93(3-4), pp. 559-85.

Furlanetto, Francesco. "Fiscal stimulus and the role of wage rigidity." Journal of Economic Dynamics and Control, April 2011, 35(4), pp. 512-27.

Galí, Jordi; López-Salido, J. David and Vallés, Javier. "Understanding the Effects of Government Spending on Consumption." Journal of the European Economic Association, March 2007, 5(1), pp. 227-70.

Galí, Jordi; Smets, Frank and Wouters, Rafael. "Unemployment in an Estimated New Keynesian Model." in Martin Eichenbaum, Erik Hurst, and Jonathan A. Parker, eds., NBER Macroeconomics Annual 2011, 26, University of Chicago Press, August 2012, pp. 329-60.

Ganong, Peter and Noel, Pascal. "Consumer Spending during Unemployment: Positive and Normative Implications." The American Economic Review, July 2019, 109(7), pp. $2383-424$.

Givens, Gregory E. "Unemployment, Imperfect Risk Sharing, and the Monetary Business Cycle." The B.E. Journal of Macroeconomics, March 2008, 8(1) (Contributions), Article 13.

. "Unemployment insurance in a sticky-price model with worker moral hazard." Journal of Economic Dynamics and Control, August 2011, 35(8), pp. 1192-214.

Gruber, Jonathan. "The Consumption Smoothing Benefits of Unemployment Insurance." The American Economic Review, March 1997, 87(1), pp. 192-205.

Hagedorn, Marcus; Manovskii, Iourii and Mitman, Kurt. "The Fiscal Multiplier." NBER Working Paper 25571, February 2019.

Hall, Robert E. "By How Much Does GDP Rise If the Government Buys More Output?" Brookings Papers on Economic Activity, Fall 2009, pp. 183-231.

Hendren, Nathaniel. "Knowledge of Future Job Loss and Implications for Unemployment Insurance." The American Economic Review, July 2017, 107(7), pp. 1778-823.

Justiniano, Alejandro; Primiceri, Giorgio E. and Tambalotti, Andrea. "Investment shocks and business cycles." Journal of Monetary Economics, March 2010, 57(2), pp. 13245 . 
Kiley, Michael T. "Policy paradoxes in the New Keynesian model." Review of Economic Dynamics, July 2016, 21, pp. 1-15.

Kimball, Miles S. "Labor-Market Dynamics When Unemployment Is a Worker Discipline Device." The American Economic Review, September 1994, 84(4), pp. 1045-59.

King, Robert G. and Watson, Mark W. "Money, Prices, Interest Rates and the Business Cycle." The Review of Economics and Statistics, February 1996, 78(1), pp. 35-53.

Kroft, Kory and Notowidigdo, Matthew J. "Should Unemployment Insurance Vary with the Unemployment Rate? Theory and Evidence." The Review of Economic Studies, July 2016, 83(3), pp. 1092-124.

Laséen, Stefan and Svensson, Lars E.O. "Anticipated Alternative Policy Rate Paths in Policy Simulations." International Journal of Central Banking, September 2011, 7(3), pp. 1-35.

Leeper, Eric M.; Traum, Nora and Walker, Todd B. "Clearing Up the Fiscal Multiplier Morass." The American Economic Review, August 2017, 107(8), pp. 2409-54.

Levin, Andrew T.; Onatski, Alexei; Williams, John C. and Williams, Noah. "Monetary Policy Under Uncertainty in Micro-Founded Macroeconometric Models." in Mark Gertler and Kenneth Rogoff, eds., NBER Macroeconomics Annual 2005, 20, MIT Press, April 2006, pp. 229-87.

Linnemann, Ludger. "The Effect of Government Spending on Private Consumption: A Puzzle?" Journal of Money, Credit and Banking, October 2006, 38(7), pp. 1715-35.

Linnemann, Ludger and Schabert, Andreas. "Can fiscal spending stimulate private consumption?" Economics Letters, February 2004, 82(2), pp. 173-9.

Ma, Eunseong. "The Heterogeneous Responses of Consumption between Poor and Rich to Government Spending Shocks." Journal of Money, Credit and Banking, October 2019, 51(7), pp. 1999-2028.

Mertens, Karel and Ravn, Morten O. "Measuring the Impact of Fiscal Policy in the Face of Anticipation: A Structural VAR Approach." The Economic Journal, May 2010, 120(544), pp. 393-413.

Monacelli, Tommaso and Perotti, Roberto. "Fiscal Policy, Wealth Effects, and Markups." NBER Working Paper No. 14584, December 2008.

Monacelli, Tommaso; Perotti, Roberto and Trigari, Antonella. "Unemployment fiscal multipliers." Journal of Monetary Economics, July 2010, 57(5), pp. 531-53. 
Mountford, Andrew and Uhlig, Harald. "What are the effects of fiscal policy shocks?" Journal of Applied Econometrics, September/October 2009, 24(6), pp. 960-92.

Nakajima, Tomoyuki. "Unemployment and indeterminacy." Journal of Economic Theory, January 2006, 126(1), pp. 314-27.

Ramey, Valerie A. "Identifying Government Spending Shocks: It's all in the Timing." The Quarterly Journal of Economics, February 2011a, 126(1), pp. 1-50.

- "Can Government Purchases Stimulate the Economy?" Journal of Economic Literature, September 2011b, 49(3), pp. 673-85.

Ravn, Morten O. and Simonelli, Saverio. "Labor Market Dynamics and the Business Cycle: Structural Evidence for the United States." The Scandinavian Journal of Economics, December 2007, 109(4), pp. 743-77.

Ravn, Morten O. and Sterk, Vincent. "Job uncertainty and deep recessions." Journal of Monetary Economics, October 2017, 90, pp. 125-41.

Romer, Christina and Bernstein, Jared. "The Job Impact of the American Recovery and Reinvestment Plan." January 9, 2009. Washington: Obama-Biden Transition Project.

Shapiro, Carl and Stiglitz, Joseph E. "Equilibrium Unemployment as a Worker Discipline Device." The American Economic Review, June 1984, 74(3), pp. 433-44.

Sims, Eric and Wolff, Jonathan. "The Output and Welfare Effects of Government Spending Shocks Over the Business Cycle." International Economic Review, August 2018, 59(3), pp. 1403-35.

Smets, Frank and Wouters, Rafael. "Shocks and Frictions in US Business Cycles: A Bayesian DSGE Approach." The American Economic Review, June 2007, 97(3), pp. 586606.

Solow, Robert M. "Another Possible Source of Wage Stickiness." Journal of Macroeconomics, Winter 1979, 1(1), pp. 79-82.

Stephens, Melvin Jr. "The Long-Run Consumption Effects of Earnings Shocks." The Review of Economics and Statistics, February 2001, 83(1), pp. 28-36.

- "Job Loss Expectations, Realizations, and Household Consumption Behavior." The Review of Economics and Statistics, February 2004, 86(1), pp. 253-69.

Uhlig, Harald. "Some Fiscal Calculus." American Economic Review: Papers \&5 Proceedings, May 2010, 100(2), pp. 30-4. 
Werning, Iván. "Managing a Liquidity Trap: Monetary and Fiscal Policy." NBER Working Paper 17344, August 2011.

Woodford, Michael. Interest and Prices: Foundations of a Theory of Monetary Policy. Princeton and Oxford: Princeton University Press, 2003.

Woodford, Michael. "Simple Analytics of the Government Expenditure Multiplier." American Economic Journal: Macroeconomics, January 2011, 3(1), pp. 1-35.

Yun, Tack. "Nominal price rigidity, money supply endogeneity, and business cycles." Journal of Monetary Economics, April 1996, 37(2), pp. 345-70.

Zubairy, Sarah. "On Fiscal Multipliers: Estimates From a Medium Scale DSGE Model." International Economic Review, February 2014, 55(1), pp. 169-95. 